\title{
PROCESOS DE CAMBIO \\ EN LA ESTRUCTURA OCUPATIVA \\ DEL SECTOR SANITARIO ESPAÑOL
}

Mauro F. Guillén

El presente artículo es un estudio básico para la planificación de la sanidad española. Se analiza, en concreto, la estructura actual y procesos de cambio del capital humano que trabaja en el sector sanitario, utilizando para ello los mejores datos disponibles, que son los del Censo de 1981. Los recursos de capital humano sanitario aparecen distribuidos geográficamente de modo desigual, siguiendo una pauta Norte-Sur (con un Norte bien dotado y un Sur relativamente desasistido). El empleo sanitario se concentra, además, en las zonas más urbanas. El modelo elitista de personal sanitario ha producido en España un sector asalariado especializado con una abundancia de personas licenciadas y una escasez de personal de enfermería, pauta que es más acusada en las regiones menos desarrolladas. El personal sanitario español se caracteriza por una elevada jerarquización, existiendo diferencias ocupativas y profesionales importantes por sexo. El análisis que realizamos sobre la evolución del personal sanitario durante las últimas tres décadas define, además, tres procesos básicos del empleo sanitario: rejuvenecimiento, feminización y urbanización. A principios de los años ochenta, el sector sanitario aparece ya como un sector grande, femenino, joven y urbano. El artículo analiza con detalle esos procesos, presentando los datos censales para el total nacional, por sectores, tipos de personal y Comunidades Autónomas. Se concluye con unas ideas 
básicas sobre el futuro del personal sanitario y los cambios que se van a producir en el capital humano del sistema de salud.

\section{El capital bumano sanitario}

El sector sanitario es uno de los sectores que más importancia social está adquiriendo en los últimos años. De ahí la creciente atención que le están prestando los políticos, los planificadores y los investigadores. Prueba de ello son los estudios sobre política y planificación sanitaria de Fuchs $(1974,1986)$, Jefferys y Sachs (1983), Sidel y Sidel (1984), De Kervasdoué et al. (1984) y McKinley (1985). El capital humano sanitario y el papel de la mujer dentro del sector han sido tratados por la Study Commission on Pharmacy (1975), McGuire (1983), Freidson (1978) y Lewin y Olesen (1985).

En las páginas que siguen se aborda un análisis estructural y dinámico de la población ocupada en el sector sanitario español, evaluando los procesos que se observan desde finales de la década de los años sesenta y su diferente distribución entre los distintos grupos profesionales sanitarios, varones y mujeres, y estratos rurales y urbanos. Se estudian, además, la estructura de edades del personal sanitario, su distribución geográfica, situación profesional y nivel de instrucción. El análisis de estas variables permite aislar los procesos de jerarquización del personal sanitario y concluir con un conjunto de proyecciones de las tendencias futuras que van a afectar al empleo dentro del sector sanitario.

Los estudios sobre la estructura y la dinámica del personal sanitario español son escasos, e insuficientes para una planificación adecuada, teniendo en cuenta la creciente importancia del sector. Entre los estudios pioneros pueden citarse los de Del Campo (1964), De Miguel (1976), Pinilla de las Heras (1977), Subsecretaría de la Seguridad Social (1977), Martín Barroso (1978) y González (1979). En los últimos años han aparecido nuevos trabajos que han supuesto un considerable avance en el conocimiento del empleo en el sector sanitario y de las profesiones sanitarias: Bernard Krief Consultants for Europe (1976a , 1976 b , 1980), Martín-Moreno y De Miguel (1982), DomínguezAlcón, Rodríguez y De Miguel (1983), Martín López (1983), De Miguel (1983, $1986 a, 1986 b$ ), Nadal (1984) y Rodríguez (1986). Pero no es hasta muy recientemente que los nuevos datos del Censo de 1981 permiten realizar un estudio global del capital humano en el sector sanitario español.

Los datos utilizados en este trabajo proceden de los censos de población, que recogen tanto un recuento de la población española como su estructura demográfica, cultural, económica y social. Para el análisis de la estructura de la población ocupada en sanidad y de los profesionales sanitarios a principios de los años ochenta, ésta es la fuente de información más reciente, fiable y completa de que se dispone. El primer censo español moderno data de 1768. 
Durante el siglo xx se han realizado censos de población referidos al 31 de diciembre de cada año terminado en cero, siendo los más fiables los de 1950 y 1970. Tanto el Censo de 1950 como el de 1970 se consideran censos de cierta calidad, a pesar de los problemas técnicos inherentes a todo censo derivados del procedimiento de obtención de los datos (la autodeclaración). El Censo de 1981 no ha sido evaluado aún con el suficiente detenimiento dada su reciente aparición. El presente análisis es, seguramente, el primero que se realiza sobre los datos referidos en ese censo al sector sanitario.

El crecimiento del empleo en los sectores de servicios ha sido particularmente intenso a partir de la segunda guerra mundial en todos los países de la OCDE (Fuchs, 1968: 15-45). En España, los últimos treinta años han supuesto una terciarización de la actividad económica. Entre los sectores con un mayor aumento de la población ocupada destacan el sector sanitario y el sector educativo, cuyos procesos de crecimiento no se ven afectados por la crisis económica de los años setenta (Cuadrado, 1986: 146; Garmendia, 1986: 51).

La evolución del empleo desde 1950 es la siguiente:

\begin{tabular}{|c|c|c|}
\hline & \multicolumn{2}{|c|}{$1950=100$} \\
\hline & 1970 & 1981 \\
\hline 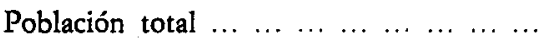 & 121 & 135 \\
\hline Población ocupada & 109 & 101 \\
\hline Sectores de servicios $\ldots \ldots \ldots \ldots \ldots$ & 162 & 189 \\
\hline Educación $\mathrm{e}$ investigación $\ldots \ldots \ldots$ & $\ldots$ & 406 \\
\hline Sector sanitario $\ldots \ldots \ldots \ldots \ldots \ldots$ & $\ldots$ & 364 \\
\hline
\end{tabular}

Mientras la población ocupada ha permanecido estable (en torno a los $10 \mathrm{mi}-$ llones y medio de personas tanto en 1950 como en 1981), el empleo en sectores de servicios se ha duplicado en el transcurso de esas tres décadas. El sector de educación e investigación ha cuadruplicado su cifra de personas ocupadas, y el sector sanitario ha multiplicado por 3,6 su personal. Las actividades de servicios representan, en 1981, casi la mitad de la ocupación total, y el sector educativo y el sector sanitario, el 4 y el 3 por 100 , respectivamente. El fenómeno de terciarización que se observa viene acompañado, pues, de un fuerte crecimiento del empleo educativo y sanitario (los datos exactos aparecen en la tabla 1). 


\section{TABLA 1}

Población ocupada por sectores y ocupaciones en 1950, 1970 y' 1981 (En números absolutos)

\begin{tabular}{|c|c|c|c|c|c|c|c|c|c|}
\hline & \multicolumn{3}{|c|}{1950} & \multicolumn{3}{|c|}{1970} & \multicolumn{3}{|c|}{1981} \\
\hline & Total & $\begin{array}{c}\text { Mujeres } \\
(\%)\end{array}$ & $\begin{array}{c}\text { Urbano: } \\
(\%)\end{array}$ & Total & $\begin{array}{c}\text { Mujeres } \\
(\%)\end{array}$ & $\begin{array}{c}\text { Urbano }^{1} \\
(\%)\end{array}$ & Total & $\begin{array}{c}\text { Mujeres } \\
(\%)\end{array}$ & $\begin{array}{c}\text { Urbano }^{\prime} \\
\left(\sigma_{0}\right)\end{array}$ \\
\hline Total de población $\ldots \ldots \ldots c k$ & 27.976 .722 & 52 & 37 & 33.956 .376 & 51 & 55 & 37.683 .363 & 51 & 63 \\
\hline Población ocupada ${ }^{2} \ldots$ & 10.576 .691 & 16 & 37 & 11.535 .365 & 20 & 56 & 10.724 .581 & 23 & 63 \\
\hline Sectores de servicios $\ldots \ldots \ldots$ & 2.620 .211 & 32 & 68 & 4.233 .013 & 29 & $\ldots$ & 4.957 .535 & 33 & 76 \\
\hline Educación e investigación & 111.133 & 53 & 58 & $\ldots$ & $\cdots$ & $\ldots$ & 450.691 & 58 & 76 \\
\hline $\begin{array}{lllll}\text { Sector } & \text { sanitario } & \ldots & \ldots & \ldots\end{array}$ & 85.296 & 35 & 68 & $\ldots$ & $\ldots$ & $\ldots$ & 310.567 & 61 & 84 \\
\hline Profesionales ocupados $\ldots \ldots \ldots$ & 287.889 & 27 & 67 & 608.384 & 33 & $\ldots$ & 996.698 & 41 & 80 \\
\hline Del sector sanitario $\ldots \ldots \ldots$ & 72.162 & 35 & 61 & 140.200 & 43 & $\ldots$ & 252.837 & 58 & 82 \\
\hline Enfermería $\ldots \ldots \ldots \ldots$ & 38.328 & 64 & 62 & $\ldots$ & $\ldots$ & $\ldots$ & 161.650 & 78 & 84 \\
\hline Ciencias sanitarias $\ldots \ldots \ldots$ & 33.834 & 3 & 60 & $\ldots$ & $\ldots$ & $\ldots$ & 91.187 & 22 & 78 \\
\hline
\end{tabular}

Notas: 'El estrato urbano incluye los núcleos de población de 10.001 habitantes o más.

Todos los datos de población ocupada para los años de 1950 y 1970 se han obtenido restando de la categoría «Población económicamente activa» las categorías «Asalariados en paro forzoso» y «Población económicamente activa en situación de paro en la semana censal», respectivamente.

Fuentes: Instituto Nacional de Estadística, Censo de la población de España y territorios de su soberania y protectorado según el empa dronamiento realizado el 31 de diciembre de 1950. Tomo III: Clasificaciones de la pablación de becho de la Peninstula e islas adyacentes obtenidas mediante una muestra del 10 por 100 (Madrid: INE, 1959), pp. 6-26, 561-597, 689-697 y 721-735; Instituto Nacional de Estadística, Censo de la población de España según la inscripción realizada el 31 de diciembre de 1970. Total nacional. Tomo III: Caracteristicas de la población (Madrid: INE, 1974), pp. 3, 30-49 y 74-78; Instituto Nacional de Estadística, Censo de población de 1981. Tomo I. Vol. I. Resultados nacionales: Caracteristicas de la pablación (Madrid: INE, 1985), pp. 5 , $7,75-95$ y $132-134$. 
El proceso de terciarización ha coincidido con un proceso de profesionalización; el número de profesionales ha crecido aún más que el empleo en los sectores de servicios:

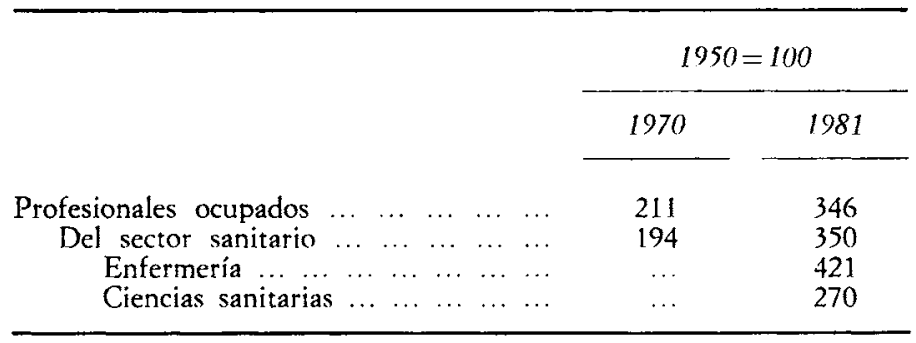

Entre 1950 y 1981 , el número de profesionales ocupados en enfermería se ha multiplicado por cuatro. Mientras que en 1950 habían sólo 1,1 enfermeras/os por cada licenciado/a en ciencias sanitarias, en 1981 la tasa había ascendido a 1,8, a pesar de que el número de licenciados/as en ciencias sanitarias había crecido en un 270 por 100 . Se puede, pues, afirmar que el aumento del número de profesionales ocupados en el sector sanitario se produce esencialmente durante la última década. La expansión del sector hospitalario público es la causa primordial del incremento del personal de enfermería.

La terciarización de la actividad económica y el incremento en el número de profesionales ocupados han venido acompañados de los procesos de teminización y urbanización del empleo en todos los niveles. No queda muy claro si hay más mujeres trabajando porque los sectores de servicios (y dentro de éstos el educativo y el sanitario) han crecido o si es la incorporación de las mujeres al mercado de trabajo lo que ha favorecido el crecimiento de los sectores terciarios. Seguramente ambas hipótesis son ciertas. En 1950, el 16 por 100 de las personas ocupadas eran mujeres, frente al 23 por 100 en 1981. Es en el sector sanitario donde tiene lugar la mayor entrada de mujeres, quienes pasan de representar el 35 por 100 del total en 1950 a nada menos que el 61 por 100 en 1981. Las mujeres son más de la mitad del empleo sanitario desde la década de los sesenta. No sólo son mayoritarias en el empleo total del sector sanitario, sino también entre el total de profesionales ocupados en el sector sanitario (un 58 por 100 son mujeres). La profesión de enfermería se ha convertido aún en una profesión más femenina que hace treinta años (64 por 100 en 1950 frente a 78 por 100 de mujeres en 1981).

El proceso de cambio en las profesiones sanitarias más importante ha tenido lugar en las personas licenciadas en ciencias sanitarias. Mientras en 1950 tan sólo el 3 por 100 de las personas con título superior de ciencias sanitarias son mujeres, en 1981 la proporción asciende al 22 por 100. La mayor afluencia de mujeres se ha producido en la profesión de Farmacia y, en menor me- 
dida, entre las personas licenciadas en Medicina (De Miguel, 1983: 81-83; 1986 b).

A partir de 1950 se produce en España un fuerte proceso de urbanización de la población. En 1950, el 37 por 100 de la población vive en núcleos de 10.000 habitantes o más, frente al 63 por 100 en 1981. La población ocupada en los sectores de servicios ya es, en 1950, urbana en una proporción del 68 por 100 . No queda muy claro, pues, si existe alguna relación entre el crecimiento de los sectores de servicios y el fenómeno de urbanización de la población. El sector sanitario es, en 1950, urbano en la misma proporción que el conjunto de las actividades terciarias, si bien su tasa de urbanización creció hasta el 84 por 100 en 1981. El sector sanitario es, pues, un sector en el que el personal es extraordinariamente urbano. Sin embargo, las diferencias por sectores y Comunidades Autónomas son importantes.

\section{Sector sanitario y profesionales sanitarios}

El sector sanitario es uno de los sectores más importantes del país, tanto desde el punto de vista de su relevancia económica (volumen de servicios prestados, presupuesto, volumen de inversión) como por el número de personas a las que da empleo. En 1981 ocupa a 310.567 personas, es decir, aproximadamente el 3 por 100 de las personas ocupadas en el país y el 6 por 100 de las que trabajan en los sectores de servicios. Dentro de los sectores de servicios, la sanidad se ve superada por el sector de educación e investigación, que da trabajo al 4 por 100 del total de personas ocupadas y al 9 por 100 de las ocupadas en el sector terciario. Pero el sector sanitario posee las dos características distintivas de las grandes actividades de servicios más acentuadas que el educativo: la proporción de mujeres empleadas en sanidad y la tasa de urbanización son las más elevadas (tabla 2 ).

El sector sanitario es fundamentalmente femenino, con un 61 por 100 de mujeres entre las personas ocupadas, frente al 57 por 100 en educación. Es, pues, una proporción doble que la del conjunto de los sectores de servicios ( 32 por 100) y triple que el conjunto de todas las actividades económicas (23 por 100). La feminización del sector sanitario - lo mismo que la del educativo- se ha producido en las dos últimas décadas. Las nuevas cohortes de personas que trabajan en el sector sanitario son mayoritariamente de mujeres. Estas han accedido a ocupaciones situadas en los estratos medios y bajos de la pirámide ocupativa sanitaria una vez que se había completado la contratación de varones en los estratos más elevados. Las mujeres ocupadas en el sector sanitario representan un porcentaje de las ocupadas en los sectores de servicios que es tres veces mayor que el de los varones (12 por 100 frente a 4 por 100). Las mujeres son más propensas que los varones a trabajar en sanidad si la comparación se realiza dentro de los sectores terciarios. Eso 
TABLA 2

Población ocupada por sectores, sexo y estratos en 1981

(En números absolutos)

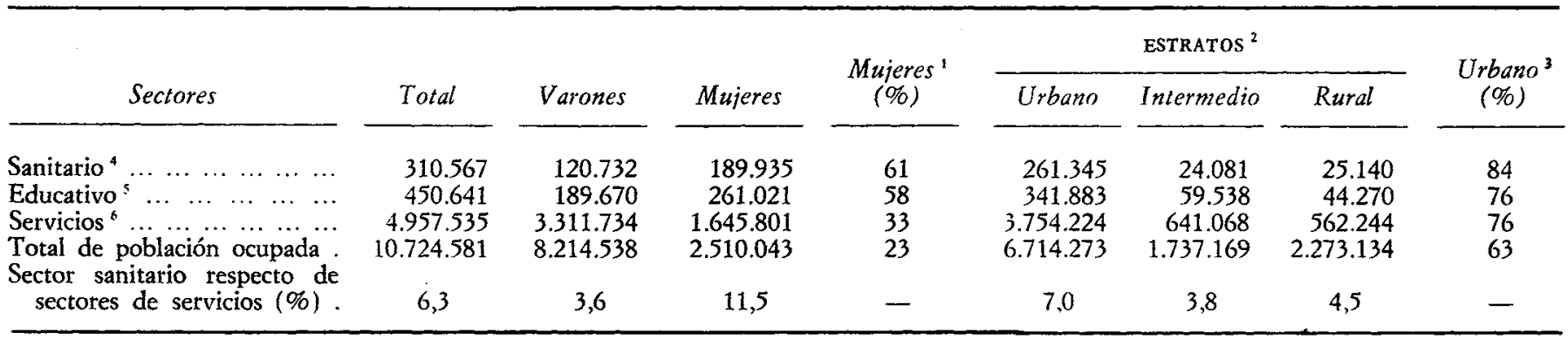

NoTAS: 'Las mujeres representan en 1981 un 51 por 100 de la población.

2 El estrato rural incluye las entidades de población con 2.000 habitantes o menos; el intermedio, desde 2.001 hasta 10.000 , y el urbano, 10.001 o más.

363 por 100 de la población vive en estratos urbanos en 1981.

4 Código 94 de la Clasificación Nacional de Actividades Económicas (CNAE) de 1974: «Sanidad y servicios veterinarios».

s Código 93 de la CNAE de 1974: «Educación e investigación».

- Códigos 61-67, 71-76, 81-86 y 91-99 de la CNAE de 1974.

Fuente: Instituto Nacional de Estadistica, Censo de población de 1981. Tomo I. Vol. I. Resultados nacionales: Caracteristicas de la población (Madrid: INE, 1985), pp. 75-84. 
puede explicarse porque históricamente las mujeres han salido del hogar para trabajar en tareas similares a las domésticas, salvo en épocas de escasez extrema de mano de obra masculina. Así, las mujeres se han dedicado al cuidado de otras personas, preferentemente de niños y niñas (sector educativo) y de personas ancianas o enfermas (sector sanitario), como si fuera el único rol femenino admitido por la sociedad tradicional (Domínguez-Alcón, Rodríguez y De Miguel, 1983: 39-55). El proceso de socialización ha presionado para que una gran cantidad de mujeres elijan carreras de enfermería, educación, puericultura y trabajo social, como un complemento socialmente aprobado (más que como una alternativa) al destino de la mujer de cuidar del marido, hijos e hijas. La mujer ha visto menoscabadas así sus oportunidades de cualificación, promoción profesional y adquisición de experiencia laboral por la subordinación profesional al varón, resultando todo lo anterior en una reducción de sus posibilidades laborales. El sector sanitario es un buen ejemplo de este proceso de dominación, pues la mayoría de los médicos son varones, y de las enfermeras son mujeres. No hay ningún otro sector ocupativo en que la dicotomía entre varones y mujeres se amolde más a una jerarquización extrema.

Además, el sector sanitario es un sector eminentemente urbano. El 84 por 100 de la población ocupada en sanidad, en 1981, se encuentra en núcleos urbanos (municipios o entidades de población de más de 10.000 habitantes), mientras el 63 por 100 de la población total o de la población ocupada es urbana. Es decir, el sector sanitario es una tercera parte más urbano que el total de la población ocupada, más urbano que los sectores de servicios e incluso que el sector educativo (que tiene una tasa del 76 por 100). La hipótesis básica es que el sector sanitario se ha vuelto más urbano con la entrada de mujeres (enfermeras) durante los años setenta, que han encontrado trabajo en los hospitales (casi totalmente situados en zonas urbanas). El sector sanitario español se distingue por su terciarismo, es decir, por una alta proporción de mujeres trabajando en el sector, y por una elevada tasa de urbanización del empleo. En la España de los años ochenta, el sector sanitario es, pues, grande, femenino y urbano.

Dentro de las ocupaciones sanitarias, los profesionales suponen el grupo más numeroso. Entre el total de personal trabajando en 1981 hay 91.187 con título superior de ciencias sanitarias (Medicina, Veterinaria y Farmacia) y 161.650 personas trabajando en enfermería (según la denominación censal, «Ayudantes técnicos sanitarios y Auxiliares en medicina, veterinaria y farmacia»). En conjunto hay, por tanto, más de un cuarto de millón de profesionales de la sanidad ocupados en España, lo que supone una cuarta parte de todos los profesionales, que son casi un millón, y cuatro quintas partes de los ocupados en el sector terciario (si bien los datos censales se refieren a profesionales sanitarios empleados en cualquier sector).

Existen 1,8 personas trabajando en enfermería por cada persona licencia- 
da en ciencias sanitarias, con la peculiaridad de que la desagregación por sexo y por estratos rurales/urbanos arroja resultados desiguales (tabla 3). Mientras una de cada cinco personas con licenciatura en ciencias sanitarias es mujer (22 por 100), lo son ya cuatro de cada cinco personas trabajando en enfermería ( 78 por 100). Hay, pues, seis veces más enfermeras que licenciadas en ciencias sanitarias, mientras que por cada enfermero hay dos licenciados.

Hay que tener en cuenta que, en España, las mujeres han accedido a las carreras superiores sanitarias muy recientemente (en Farmacia son ya, por primera vez, más de la mitad), pues durante décadas España mantuvo la tasa mínima de mujeres-médicas de todo el mundo (junto con los Estados Unidos). El acceso de la mujer a las carreras medias de enfermería ha sido históricamente muy elevado, si bien los varones están entrando cada vez en números absolutos mayores (aunque no relativos). El modelo varón-licenciado (sobre todo médico-varón) y mujer-enfermera domina la estructura profesional sanitaria, por el momento. La tasa de feminización del conjunto de las ciencias sanitarias y de la enfermería ( 58 por 100 ) es superior a la del colectivo de todos los profesionales (41 por 100). De entre todos los profesionales (varones y mujeres), las mujeres son doblemente propensas a haber estudiado ciencias sanitarias o enfermería que los varones ( 36 por 100 frente a 18 por 100), porque históricamente la mujer ha sido admitida sólo en algunas ocupaciones (las relacionadas con el cuidado de las personas) y hacia los estudios más cortos en duración, menos cualificados $y$, consiguientemente, asociados con puestos de trabajo peor remunerados y con menor poder.

Las personas ocupadas en el sector sanitario se distribuyen geográficamente de modo desigual, con un Norte con abundancia de trabajadores sanitarios y un Sur con relativa escasez. En el conjunto del país hay 8,2 trabajadores sanitarios por cada 1.000 habitantes. La tasa es inferior a 7,3 para las Comunidades Autónomas situadas al sur de la Península y, también, para Galicia. Las Comunidades Autónomas de la mitad norte son las que mantienen una tasa más alta de trabajadores sanitarios per capita. En la tabla 4 se pueden observar las tasas por 1.000 habitantes de las Comunidades Autónomas en 1981, ordenadas de mayor a menor renta per capita. En general, mayor renta per capita está asociada con una tasa mayor de trabajadores sanitarios, si bien a niveles elevados de renta entran en juego otras variables (sanitarias) como la tasa de camas hospitalarias y el número de estudiantes de carreras sanitarias (González, 1979: 43). Hay, no obstante, dos excepciones notables: Cantabria y Navarra. Estas dos comunidades tienen una renta per capita inferior a la de Madrid, Cataluña o el País Vasco, pero tienen hasta un 40 por 100 más personal sanitario ocupado. Navarra, con 12,3 personas ocupadas en el sector sanitario por cada 1.000 habitantes, es la Comunidad Autónoma con una tasa más elevada. Existen razones estratégicas que explican la abundancia relativa de trabajadores del sector sanitario en Navarra y Cantabria: en ambos casos se trata de Comunidades Autónomas uniprovin- 


\section{TABLA 3}

Profesionales ocupados, por sexo y estratos, en 1981

(En números absolutos)

\begin{tabular}{|c|c|c|c|c|c|c|c|c|}
\hline \multirow[b]{2}{*}{ Profesiones } & \multirow[b]{2}{*}{ Total } & \multirow[b]{2}{*}{ Varones } & \multirow[b]{2}{*}{ Mujeres } & \multirow{2}{*}{$\begin{array}{l}\text { Mujeres }{ }^{1} \\
\text { (\%) }\end{array}$} & \multicolumn{3}{|c|}{ ESTRATOS ${ }^{2}$} & \multirow{2}{*}{$\begin{array}{l}\text { Urbano }^{3} \\
(\%)\end{array}$} \\
\hline & & & & & Urbano & Intermedio & Rural & \\
\hline Ciencias sanitarias ${ }^{4} \ldots$ & 91.187 & 71.326 & 19.861 & 22 & 71.428 & 9.403 & 10.356 & 78 \\
\hline $\begin{array}{lllllll}\text { Enfermería }^{s} & \ldots & \ldots & \ldots & \ldots & \ldots\end{array}$ & 161.650 & 35.388 & 126.262 & 78 & 136.652 & 13.087 & 11.911 & 84 \\
\hline Total ciencias sanitarias y en- & 252837 & 106714 & 146123 & 58 & 208080 & 22490 & 22267 & 82 \\
\hline 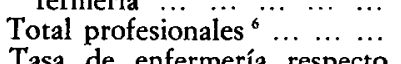 & 996.698 & 586.692 & $\begin{array}{l}140.123 \\
409.737\end{array}$ & 41 & 799.661 & 106.584 & 90.454 & $\begin{array}{l}8< \\
80\end{array}$ \\
\hline $\begin{array}{l}\text { 1asa de entermeria respecto } \\
\text { a ciencias sanitarias } \ldots \ldots \\
\text { Ciencias sanitarias y enferme- }\end{array}$ & 1,8 & 0,5 & 6,4 & - & 1,9 & 1,4 & 1,2 & - \\
\hline fesionales $(\%) \ldots \ldots \ldots \ldots$ & 25,4 & 18,2 & 35,7 & - & 26,0 & 21,1 & 24,6 & - \\
\hline
\end{tabular}

Notas: 'Las mujeres representan en 1981 un 51 por 100 de la población.

2 El estrato rural incluye las entidades de población con 2.000 o menos; el intermedio, desde 2.001 hasta 10.000 , y el urbano, 10.001 o más.

${ }^{3}$ El 63 por 100 de la población vive en estratos urbanos en 1981

${ }^{4} \mathrm{Se}$ incluyen «Médicos, veterinarios, farmacéuticos y similares», código 06 de la Clasificación Nacional de Ocupaciones (CNO) de 1979.

" "Ayudantes técnicos sanitarios y Auxiliares en medicina, veterinaria y farmacia", código 07 de la CNO de 1979.

" «Profesionales, técnicos y similares» (códigos 01-09 y 11-19), a excepción de «Miembros del clero y similares» (código 14 de la CNO de 1979), que suman 34.472 personas.

Fuenre: Instituto Nacional de Estadística, Censo de población de 1981. Tomo I. Vol. I. Resultados nacionales: Características de la población (Madrid: INE, 1985), pp. 85-95 y 132-134. 
TABLA 4

Personal sanitario en las Comunidades Autónomas, en 1981

(En números absolutos y tasas por 1.000 habitantes)

\begin{tabular}{|c|c|c|c|c|c|c|c|c|c|c|c|c|c|}
\hline \multirow[b]{2}{*}{ Compnidades Autónomas ${ }^{1}$} & \multicolumn{3}{|c|}{ SECTOR SANITARIO } & \multicolumn{3}{|c|}{$\begin{array}{l}\text { TOTAL CIENCIAS SANI- } \\
\text { TARIAS Y ENFER MERIA }\end{array}$} & \multicolumn{3}{|c|}{ CIENCIAS SANITARIAS } & \multicolumn{3}{|c|}{ ENFERMERIA } & \multirow{2}{*}{$\begin{array}{l}\text { Tasa } \\
\text { entermeria } \\
\text { respecto a } \\
\text { ciencias } \\
\text { sanitarias }\end{array}$} \\
\hline & Total & $\begin{array}{c}\text { Por } \\
\text { mil } \\
\text { bab. }\end{array}$ & $\begin{array}{l}\text { Pob. } \\
o c u \text {. } \\
\text { (\%) }\end{array}$ & Total & $\begin{array}{c}\text { Por } \\
\text { mil } \\
\text { hab. }\end{array}$ & $\begin{array}{c}\mathrm{Mu}- \\
\mathrm{jer}{ }^{2} \\
(\%)\end{array}$ & Total & $\begin{array}{c}\text { Por } \\
\text { mil } \\
\text { bab. }\end{array}$ & $\begin{array}{l}M u- \\
\text { jer } \\
\text { (\%) }\end{array}$ & Total & $\begin{array}{c}\text { Por } \\
\text { mil } \\
\text { bab. }\end{array}$ & $\begin{array}{c}M u- \\
j e r^{2} \\
(\%)\end{array}$ & \\
\hline Comunidad de Madrid & 49.614 & 10,5 & 3,9 & 41.476 & 8,8 & 59,5 & 14.697 & 2,5 & 24,8 & 26.779 & 5,7 & 77,9 & 1,8 \\
\hline $\begin{array}{lllllll}\text { Baleares } & \ldots & \ldots & \ldots & \ldots & \ldots & \ldots\end{array}$ & 5.654 & 8,3 & 2,6 & 4.261 & 6,2 & 56,8 & 1.652 & 2,4 & 16,6 & 2.609 & 3,8 & 82,3 & 1,6 \\
\hline $\begin{array}{llllllll}\text { Cataluña } & \ldots & \ldots & \ldots & \ldots & \ldots & \ldots & \ldots\end{array}$ & 50.957 & 8,6 & 2,7 & 42.068 & 7,1 & 59,8 & 14.914 & 2,5 & 24,8 & 27.154 & 4,6 & 79,1 & 1,8 \\
\hline $\begin{array}{llllllll}\text { País Vasco } & \ldots & \ldots & \ldots & \ldots & \ldots & \ldots & \ldots\end{array}$ & 18.809 & 8,8 & 2,9 & 15.492 & 7,2 & 66,6 & 4.927 & 2,3 & 25,0 & 10.565 & 4,9 & 86,0 & 2,1 \\
\hline $\begin{array}{llllllll}\text { Cantabria } & \ldots & \ldots & \ldots & \ldots & \ldots & \ldots & \ldots\end{array}$ & 5.432 & 10,6 & 3,6 & 4.391 & 8,6 & 64,1 & 1.243 & 2,4 & 15,2 & 3.148 & 6,2 & 83,4 & 2,5 \\
\hline $\begin{array}{cccccccc}\text { Navarra } & \ldots & \ldots & \ldots & \ldots & \ldots & \ldots & \ldots\end{array}$ & 6.261 & 12,3 & 3,9 & 5.374 & 10,6 & 68,1 & 1.680 & 3,3 & 26,1 & 3.694 & 7,3 & 87,3 & 2,2 \\
\hline 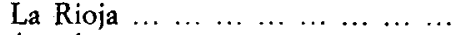 & 2.154 & 8,5 & 2,6 & 1.822 & 7,2 & 60,9 & 606 & 2,4 & 15,0 & 1.216 & 4,8 & 83,8 & 2,0 \\
\hline $\begin{array}{llllllll}\text { Aragón } & \ldots & \ldots & \ldots & \ldots & \ldots & \ldots & \ldots\end{array}$ & 11.591 & 9,6 & 3,2 & 9.714 & 8,0 & 58,0 & 3.857 & 3,2 & 22,6 & 5.857 & 4,8 & 81,4 & 1,5 \\
\hline Comunidad Valenciana $\ldots . .$. . & 27.928 & 7,7 & 2,7 & 23.230 & 6,4 & 55,3 & 8.051 & 2,2 & 20,1 & 15.179 & 4,2 & 74,0 & 1,9 \\
\hline Asturias ... . & 9.705 & 8,6 & 3,0 & 7.646 & 6,8 & 56,9 & 2.739 & 2,4 & 23,2 & 4.907 & 4,4 & 75,6 & 1,8 \\
\hline $\begin{array}{ccccccc}\text { Canarias } & \ldots & \ldots & \ldots & \ldots & \ldots & \ldots\end{array}$ & 11.207 & 7,8 & 3,2 & 7.869 & 5,4 & 55,9 & 2.639 & 1,8 & 15,8 & 5.230 & 3,6 & 76 & 2,0 \\
\hline $\begin{array}{lllllll}\text { Castilla-León } & \ldots & \ldots & \ldots & \ldots & \ldots & \ldots\end{array}$ & 22.414 & 8,7 & 3,0 & 18.545 & 7,2 & 56,6 & 7.736 & 3,0 & 19,9 & 10.809 & 4,2 & 82,9 & 1,4 \\
\hline $\begin{array}{ccccccccc}\text { Galicia } & \ldots & \ldots & \ldots & \ldots & \ldots & \ldots & \ldots & \ldots\end{array}$ & 18.011 & 6,5 & 1,9 & 13.596 & 4,9 & 58,0 & 5.322 & 1,9 & 23,0 & 8.274 & 3,0 & 80,4 & 1,6 \\
\hline $\begin{array}{lllllllll}\text { Murcia } & \ldots & \ldots & \ldots & \ldots & \ldots & \ldots & \ldots & \ldots\end{array}$ & 6.695 & 7,0 & 2,7 & 5.565 & 5,9 & 50,5 & 1.875 & 2,0 & 15,3 & 3.690 & & 68,4 & 2,0 \\
\hline $\begin{array}{llllllll}\text { Andalucía } & \ldots & \ldots & \ldots & \ldots & \ldots & \ldots & \ldots\end{array}$ & 46.753 & 7,3 & 2,7 & 37.465 & 5,8 & 53,7 & 13.565 & 2,1 & 19,0 & 23.900 & 3,7 & 73,4 & 1,8 \\
\hline Castilla-La Mancha $\ldots \ldots \ldots$. & 9.619 & 5,9 & 2,2 & 7.925 & 4,9 & 52,0 & 3.258 & 2,0 & 15,9 & 4.667 & 2,9 & 77,2 & 1,4 \\
\hline $\begin{array}{llllllll}\text { Extremadura } & \ldots & \ldots & \ldots & \ldots & \ldots & \ldots\end{array}$ & 6.773 & 6,4 & 2,6 & 5.611 & 5,4 & 51,3 & 2.180 & 2,1 & 17,8 & 3.431 & 3,3 & 72,7 & 1,6 \\
\hline TotaL $^{3} \ldots \ldots \ldots \ldots$ & 310.567 & 8,2 & 6,9 & 252.837 & 6,7 & 57,8 & 91.187 & 2,4 & 21,8 & 161.650 & 4,3 & 78,1 & 1,8 \\
\hline
\end{tabular}

Notas: 1 Ordenadas según la renta per capita. Banco de Bilbao, Renta nacional de España y su distribución provincial 198I (Bilbao: Banco de Bilbao. 1983), p. 76.

representan en 1981 un 51 por 100 de la población.

3 Se incluyen las personas ocupadas en Ceuta y Melilla.

FuENTEs: Instituto Nacional de Estadística, Censo de población de 1981. Tomo II. Resiltados por Comunidades Autónomas. I.a parte: Caracteristicas de la población (Madrid: INE, 1985); Instituto Nacional de Estadistica, Censo de población de l981. Tomo l. Volumen I. Resitiados nacionales: Caracteristicas de la población (Madrid: INE, 1985), pp. 5, 75, 85 y 89. 
ciales, con un alto grado de desarrollo, en el norte de la Península y con hospitales clínicos importantes. En el caso navarro existe, además, una Universidad privada con Facultad de Medicina y una Diputación Foral potente que dispone de su propia red asistencial.

El sur de la Península y Galicia mantienen tan sólo la mitad de población ocupada en sanidad por cada 1.000 habitantes que Navarra o Cantabria. Así, Castilla-La Mancha tiene solamente 5,9 personas trabajando en el sector sanitario por cada 1.000 habitantes, y Extremadura y Galicia, 6,4 y 6,5, respectivamente. Existen dos Comunidades Autónomas (Asturias y Castilla-León) que están por debajo de la media nacional en cuanto a renta per capita $\mathrm{y}$, sin embargo, están por debajo de la media en cuanto a personal sanitario. La Comunidad Valenciana (con una renta per capita similar a la del conjunto nacional) tiene 7,7 trabajadores sanitarios por cada 1.000 habitantes $(0,5$ menos que la media). Ninguna comunidad con una renta per capita superior a la media tiene menos trabajadores sanitarios que la media.

Según las diversas Comunidades Autónomas, el personal sanitario supone porcentajes de la población ocupada muy diferentes también. El porcentaje más reducido (Galicia) es la mitad que el más elevado (Madrid y Navarra). Este indicador correlaciona positivamente con el número de trabajadores sanitarios por cada 1.000 habitantes. Los casos de Cataluña, La Rioja, Baleares y Canarias son, sin embargo, peculiares: en las tres primeras comunidades las personas ocupadas en el sector sanitario representan un porcentaje de la población ocupada total menor que la media. Con los datos disponibles es difícil saber la razón de esa discrepancia. El caso canario es el inverso, y puede deberse a que la población ocupada es más reducida que en êl resto de las comunidades.

Las personas licenciadas en cualquiera de las tres carreras sanitarias en 1981 se distribuyen también de modo desigual según las Comunidades Autónomas, aunque son las/os profesionales de la enfermería los que están peor distribuidos. Las comunidades peor dotadas de personal licenciado en ciencias sanitarias son las situadas en el sur de la Península, Galicia y Canarias (con una tasa en torno a 1,8 por cada 1.000 habitantes). Esa tasa es casi la mitad que la de Navarra, que es la Comunidad Autónoma con más personal sanitario titulado superior $(3,3)$. Las zonas más pobres del Sur (además de Galicia) tienen menos de 2,1 licenciados/as en ciencias sanitarias por cada 1.000 habitantes, mientras que el Norte tiene tasas superiores a la media de 2,4 por cada 1.000 habitantes. Navarra, con 3,3 personas licenciadas por cada 1.000 habitantes; Aragón, con 3,2, y Castilla-León, con 3,0, son las comunidades mejor dotadas.

Otra hipótesis para explicar el modelo Norte-Sur de la distribución de licenciados es el régimen de propiedad, especialmente de la tierra. En el Norte, el minifundismo favorece una mejor distribución de la propiedad y, por tanto, una posibilidad mayor de la población de acceder a tratamiento médico. 
Esta explicación atañe esencialmente a los casos de Aragón y Castilla-León. Hay, no obstante, una excepción -el País Vasco- que cuenta con menos licenciados/as por cada 1.000 habitantes que la media nacional. Eso indica que una segunda variable - la disponibilidad de personas recién licenciadas de las Facultades - incide de forma importante en las tasas. El País Vasco tiene una Facultad de Medicina relativamente pequeña y carece de Facultades de Veterinaria y Farmacia. Por el contrario, Navarra, con la tasa más elevada de todas las comunidades, posee una Facultad de Medicina relativamente grande y otra de Farmacia, además de una amplia red hospitalaria. En general, mayor renta per capita significa mayor dotación de personas licenciadas por habitante, aunque el modelo Norte-Sur aparece también mediatizado por el hecho de que en la comunidad existan Facultades grandes o redes hospitalarias importantes.

Las tasas por 1.000 habitantes de personal de enfermería en las distintas Comunidades Autónomas proporciona un indicador indirecto de la dotación de centros sanitarios (esencialmente hospitales). Las comunidades con tasas más elevadas de enfermeras/os son comunidades con una renta per capita alta, situadas además en la mitad norte de la Península y dotadas de importantes sectores hospitalarios. Navarra y Cantabria son las dos comunidades con tasas más elevadas (7,3 y 6,2 enfermeras/os por cada 1.000 habitantes). En el otro extremo, todas las comunidades del sur de la Península tienen tasas inferiores a la media nacional. La comunidad peor dotada es CastillaLa Mancha, con tan sólo 2,9 enfermeras/os por cada 1.000 habitantes, es decir, menos de la mitad que Navarra. Esta situación se ve seguramente agravada por el fenómeno de concentración de recursos de todo tipo en Madrid. En el grupo de los peor dotados hay que incluir a las islas, por razones fundamentalmente geográficas: Baleares ( 3,8 por cada 1.000 habitantes) y Canarias $(3,6)$. Las islas Baleares tienen más licenciados pero menos enfermeras que la media. El País Vasco sigue la pauta inversa. Nuevamente, las mayores tasas de enfermeras/os se corresponden con el nivel de renta per capita de la comunidad, por el hecho de que se disponga de titulados y -esencialmentepor la importancia del sector hospitalario; si bien la distribución geográfica de las camas hospitalarias todavía sigue una pauta Este-Oeste (De Miguel, 1986: 235), aunque se está transformando en una Norte-Sur y periferiainterior.

La relación entre las tasas de enfermeras/os y las de licenciados/as en ciencias sanitarias sigue pautas menos explicables. No existe una relación clara con la renta per capita, si bien Cantabria y Navarra $(2,5$ y 2,2 , respectivamente) tienen una tasa bastante superior a la media nacional $(1,8)$ y comunidades como Canarias, Murcia y Andalucía también la superan o igualan. Las Comunidades Autónomas más desarrolladas — como Baleares, Cataluña y Aragón- tienen tasas inferiores o iguales a la media nacional. Hay que recurrir, pues, a otro tipo de variables para explicar las variaciones espaciales de esta 
tasa. Las comunidades con una alta renta per capita pero bajas tasas de enfermeras/os por cada licenciado/a son comunidades con régimen minifundista de propiedad de la tierra (caso de Aragón y de Castilla-León), lo que resulta en un mayor número de médicos, veterinarios y farmacéuticos más que en un menor número de enfermeras/os. Canarias, Murcia y Andalucía - con tasas superiores a lo que cabría esperar- tienen comparativamente más enfermeras/os por cada 1.000 habitantes que licenciados/as, lo que resulta en mayores tasas de enfermeras/os por cada licenciado/a. La comunidad con una tasa menor es Castilla-La Mancha (1,4 enfermeras/os por cada licenciado/a), casi la mitad que la de Cantabria (2,5), que es la más elevada.

En las comunidades más ricas existen más mujeres ocupadas con título superior de ciencias sanitarias. Mientras la tasa media de feminización es del 22 por 100 , las mujeres representan en la Comunidad de Madrid y en Cataluña un 25 por 100 del empleo de los licenciados sanitarios, y un 26 por 100 en Navarra. Hay, sin embargo, dos comunidades con tasas muy elevadas no explicables únicamente por su nivel de desarrollo: Asturias y Galicia (con tasas del 23 por 100) están por encima de la media nacional, pero por debajo en cuanto a riqueza. Una explicación de este fenómeno es que una mejor situación relativa de la mujer en esas dos regiones facilita el acceso de las mujeres a muchas carreras, entre ellas la médica, veterinaria o farmacéutica. Las comunidades menos desarrolladas (el Sur) tienen tasas reducidas, pero es La Rioja (15 por 100) la comunidad con la tasa más pequeña. Una explicación puede ser la falta de Facultades en esa Comunidad Autónoma.

El número de personas ocupadas en el sector sanitario en 1981 es importante. Se caracteriza por ser un sector de servicios típico dadas sus altas tasas de feminización y urbanización. La jerarquización ocupativa por sexo es, sin embargo, acusada y se resume en el modelo básico de que los varones son licenciados en carreras sanitarias y las mujeres son enfermeras. Existen también diferencias notables en la distribución geográfica del capital humano sanitario, con un Norte relativamente bien dotado y un Sur con escasez de personal sanitario. El nivel de desarrollo de las distintas Comunidades Autónomas está asociado con el nivel de dotación de personal sanitario, aunque otro tipo de variables, como la estructura de la propiedad y la existencia de centros universitarios y hospitalarios importantes, explican también las desigualdades espaciales observadas.

\section{Tres procesos de jerarquización}

La dinámica del empleo en el sector sanitario desde finales de los años sesenta se produce siguiendo tres procesos de cambio que acarrean una jerarquización creciente del sector. Recientemente, el sector sanitario ha experimentado un intenso proceso de rejuvenecimiento a través, principalmente, de 
la incorporación de mujeres, con lo que, además, el sector se ha feminizado progresivamente. El proceso de rejuvenecimiento afecta de modo desigual a varones y mujeres, a las personas licenciadas en ciencias sanitarias y al personal de enfermería. El tercer proceso de jerarquización es el de la urbanización creciente del sector sanitario, por lo menos hasta finales de los años setenta. En los años inmediatamente anteriores al Censo de 1981 se observa un cierto crecimiento del empleo en las zonas rurales, donde al parecer están encontrando trabajo las personas más jóvenes.

La población ocupada en el sector sanitario es joven. En 1981, según los datos censales, más de la mitad (53 por 100) tiene menos de 35 años. Desde mediados de los años sesenta se ha producido un proceso de rejuvenecimiento de la ocupación sanitaria. Como era de esperar, las mujeres son más jóvenes que los varones: el 62 por 100 de las mujeres tiene menos de 35 años, frente al 43 por 100 de los varones. La cohorte femenina más numerosa es la comprendida entre los 25 y los 34 años ( 42 por 100), que se corresponde con el inicio de la entrada de personal de enfermería en los hospitales, sobre todo a partir del comienzo de la década de los setenta (tablas 5 y 6 ).

Solamente el 6 por 100 de los varones ocupados en el sector sanitario tiene menos de 24 años, frente al 20 por 100 de las mujeres. Este hecho se produce porque hay más varones que son licenciados y, sin embargo, más mujeres enfermeras. Dado que enfermería es una carrera más corta, las mujeres pueden ser, lógicamente, más jóvenes cuando acaban sus estudios. Además, la entrada de varones-licenciados se ha visto disminuida en favor de la entrada de mujeres-enfermeras durante los años setenta, a consecuencia de la saturación de médicos en el sector público sanitario. El 19 por 100 de los varones tiene 55 años o más, frente al 22 por 100 de las mujeres. Todos estos datos demuestran que el proceso de feminización en sanidad continúa todavía, así como la intensificación de la entrada de mujeres en el sector en todos los niveles ocupativos y profesionales, y no solamente en enfermería. La proporción de mujeres es alta para las personas ocupadas comprendidas entre 16 y 19 años de edad ( 83 por 100 ) y entre 20 y 24 ( 83 por 100 ), pero desciende progresivamente hasta los $65-69$ años (34 por 100) debido a que las mujeres no accedieron en números importantes al sector hasta la década de los setenta. A partir de los 70 años de edad, la proporción de mujeres se incrementa de nuevo a causa de la mortalidad mayor de los varones.

En 1981, la población ocupada con título superior de ciencias sanitarias (es decir, con licenciatura en Medicina, Veterinaria o Farmacia) representa 91.187 personas, de las que el 22 por 100 son mujeres. Se trata de una población relativamente joven, pues el 42 por 100 tiene menos de 35 años, es decir, casi la mitad de las personas licenciadas en ciencias sanitarias ocupadas en 1981 concluyeron sus estudios en la década de los años setenta (véanse las tablas 7 y 8). Esta proporción es similar para el total de la población ocupada y para la población ocupada en los sectores de servicios, pero inferior a la del 
TABLA 5

Personal del sector sanitario por grupos de edad, sexo y estratos en 1981 (En números absolutos)

\begin{tabular}{|c|c|c|c|c|c|c|c|c|}
\hline \multirow[b]{2}{*}{ Grupos de edad (en años) } & \multirow[b]{2}{*}{ Total } & \multirow[b]{2}{*}{ Varones } & \multirow[b]{2}{*}{ Mujeres } & \multirow{2}{*}{$\begin{array}{c}\text { Mujeres } \\
(\%)\end{array}$} & \multicolumn{3}{|c|}{ ESTRATOS $^{2}$} & \multirow{2}{*}{$\begin{array}{c}\text { Urbano } \\
(\%)\end{array}$} \\
\hline & & & & & Urbano & Intermedio & Rural & \\
\hline De 16 a $19 \ldots \ldots \ldots \ldots$ & 4.467 & 862 & 3.605 & 80,7 & 3.404 & 483 & 580 & 76,2 \\
\hline $\begin{array}{cccccccc}20-24 & \ldots & \ldots & \ldots & \ldots & \ldots & \ldots & \ldots\end{array}$ & 40.871 & 7.016 & 33.855 & 82,8 & 32.882 & 3.626 & 4.363 & 80,5 \\
\hline $\begin{array}{llllllll}25.29 & \ldots & \ldots & \ldots & \ldots & \ldots & \ldots & \ldots\end{array}$ & 70.953 & 21.286 & 49.667 & 70,0 & 58.497 & 5.689 & 6.767 & 82,4 \\
\hline $\begin{array}{ccccccc}30-34 & \ldots & \ldots & \ldots & \ldots & \ldots & \ldots\end{array}$ & 48.268 & 18.300 & 29.967 & 62,1 & 41.502 & 3.287 & 3.479 & 86,0 \\
\hline $\begin{array}{lllllllll}35-39 & \ldots & \ldots & \ldots & \ldots & \ldots & \ldots & \ldots\end{array}$ & 31.270 & 13.991 & 17.279 & 55,3 & 27.285 & 2.055 & 1.930 & 87,2 \\
\hline $\begin{array}{llllllll}40-44 & \ldots & \ldots & \ldots & \ldots & \ldots & \ldots & \ldots\end{array}$ & 23.809 & 10.614 & 13.195 & 55,4 & 20.889 & 1.553 & 1.366 & 87,7 \\
\hline $\begin{array}{llllllll}45.49 & \ldots & \ldots & \ldots & \ldots & \ldots & \ldots & \ldots\end{array}$ & 26.586 & 12.787 & 13.800 & 52,0 & 22.899 & 1.899 & 1.788 & 86,1 \\
\hline $\begin{array}{cccccccc}50-54 & \ldots & \ldots & \ldots & \ldots & \ldots & \ldots & \ldots\end{array}$ & 25.139 & 12.936 & 12.203 & 48,5 & 21.489 & 1.998 & 1.653 & 85,5 \\
\hline $\begin{array}{llllllll}55-59 & \ldots & \ldots & \ldots & \ldots & \ldots & \ldots & \ldots\end{array}$ & 20.372 & 11.557 & 8.815 & 43,2 & 17.111 & 1.661 & 1.600 & 84,0 \\
\hline $\begin{array}{cccccccc}60-64 & \ldots & \ldots & \ldots & \ldots & \ldots & \ldots & \ldots\end{array}$ & 12.026 & 7.088 & 4.938 & 41,1 & 9.975 & 1.154 & 898 & 82,9 \\
\hline $\begin{array}{llllllll}65-69 & \ldots & \ldots & \ldots & \ldots & \ldots & \ldots & \ldots\end{array}$ & 5.318 & 3.533 & 1.785 & 33,6 & 4.167 & 562 & 589 & 78,4 \\
\hline $\begin{array}{cccccccc}70-74 & \ldots & \ldots & \ldots & \ldots & \ldots & \ldots & \ldots\end{array}$ & 833 & 428 & 405 & 48,6 & 716 & 47 & 70 & 86,0 \\
\hline De 75 o más $\ldots \ldots \ldots \ldots$ & 655 & 333 & 321 & 49,0 & 530 & 67 & 58 & 80,9 \\
\hline $\begin{array}{llllll}\text { Total } & \ldots & \ldots & \ldots & \ldots & \ldots\end{array}$ & 310.567 & 120.732 & 189.835 & 61,1 & 261.345 & 24.081 & 25.140 & 84,2 \\
\hline
\end{tabular}

Notas: El sector sanitario se corresponde con «Sanidad y servicios veterinarios» (código 94 de la Clasificación Nacional de Actividades Económicas de 1974).

1 Las mujeres representan en 1981 un 51 por 100 de la población.

2 El estrato rural incluye los núcleos de población con 2.000 habitantes o menos; el intermedio, desde 2.001 hasta 10.000 , y el urbano, 10.001 o más.

${ }^{3}$ El 63 por 100 de la población vive en estratos urbanos en 1981

Fuente: Instituto Nacional de Estadística, Censo de población de 1981. Tomo I. Vol. I. Resultados nacionales: Características de la población (Madrid: INE, 1985), pp. 75-80. 
TABLA 6

Personal del sector sanitario por grupos de edad, sexo y estratos en 1981

(En porcentajes)

\begin{tabular}{|c|c|c|c|c|c|c|}
\hline \multirow[b]{2}{*}{ Grupos de edad (en años) } & \multirow[b]{2}{*}{$\begin{array}{c}\text { Total } \\
(\%)\end{array}$} & \multirow[b]{2}{*}{$\begin{array}{c}\text { Varones } \\
(\%)\end{array}$} & \multirow[b]{2}{*}{$\begin{array}{l}\text { Mujeres } \\
(\%)\end{array}$} & \multicolumn{3}{|c|}{ ESTRATOS * } \\
\hline & & & & $\begin{array}{c}\text { Urbano } \\
(\%)\end{array}$ & $\begin{array}{l}\text { Intermedio } \\
(\%)\end{array}$ & $\begin{array}{l}\text { Rural } \\
(\%)\end{array}$ \\
\hline 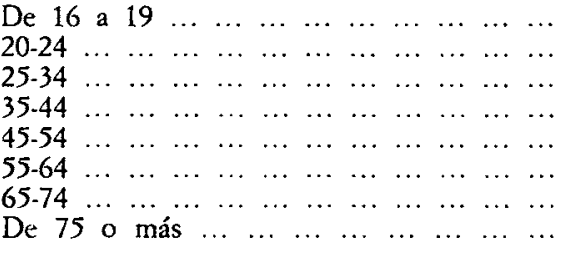 & $\begin{array}{r}1,4 \\
13,7 \\
38,3 \\
17,7 \\
16,7 \\
10,5 \\
1,9 \\
0,2\end{array}$ & $\begin{array}{r}0,7 \\
5,8 \\
32,8 \\
20,4 \\
21,3 \\
15,5 \\
3,3 \\
0,3\end{array}$ & $\begin{array}{r}1,9 \\
17,8 \\
41,9 \\
16,1 \\
13,7 \\
7,2 \\
1,1 \\
0,2\end{array}$ & $\begin{array}{r}1,3 \\
12,6 \\
38,1 \\
18,4 \\
17,0 \\
10,3 \\
1,9 \\
0,2\end{array}$ & $\begin{array}{r}2,0 \\
15,1 \\
37,2 \\
15,0 \\
16,2 \\
11,7 \\
2,5 \\
0,3\end{array}$ & $\begin{array}{r}2,3 \\
17,3 \\
40,8 \\
13,1 \\
13,7 \\
9,9 \\
2,6 \\
0,2\end{array}$ \\
\hline $\begin{array}{llllllllll}\text { Total } & \ldots & \ldots & \ldots & \ldots & \ldots & \ldots & \ldots & \ldots & \ldots\end{array}$ & $\begin{array}{c}100,0 \\
(310.567)\end{array}$ & $\begin{array}{c}100,0 \\
(120.732)\end{array}$ & $\begin{array}{c}100,0 \\
(189.835)\end{array}$ & $\begin{array}{c}100,0 \\
(261.345)\end{array}$ & $\begin{array}{c}100,0 \\
(24.081)\end{array}$ & $\begin{array}{c}100,0 \\
(25.140)\end{array}$ \\
\hline
\end{tabular}

NotaS: El sector sanitario se corresponde con «Sanidad y servicios veterinarios» (código 94 de la Clasificación Nacional de Actividades Económicas de 1974).

* El estrato rural incluye los núcleos de población con 2.000 habitantes o menos; el intermedio, desde 2.001 hasta 10.000 , y el urbano, 10.001 o más.

Fuente: Instituto Nacional de Estadística, Censo de población de 1981. Tomo I. Vol. I. Resultados nacionales: Características de la población (Madrid: INE, 1985), pp. 75-80. 


\section{TABLA 7}

Personal con título superior de ciencias sanitarias, por grupos de edad, sexo y estratos, en 1981 (En números absolutos)

\begin{tabular}{|c|c|c|c|c|c|c|c|c|}
\hline \multirow[b]{2}{*}{ Grupos de edad (en años) } & \multirow[b]{2}{*}{ Total } & \multirow[b]{2}{*}{ Varones } & \multirow[b]{2}{*}{ Mujeres } & \multirow{2}{*}{$\begin{array}{c}\text { Mujeres' } \\
\text { (\%) }\end{array}$} & \multicolumn{3}{|c|}{ ESTRATOS $^{2}$} & \multirow{2}{*}{$\begin{array}{c}\text { Urbano } \\
(\%)\end{array}$} \\
\hline & & & & & Urbano & Intermedio & Rural & \\
\hline $\begin{array}{llllllll}\text { Hasta } & 24 & \ldots & \ldots & \ldots & \ldots & \ldots & \ldots\end{array}$ & 3.058 & 1.685 & 1.373 & 44,9 & 2.353 & 292 & 413 & 76,9 \\
\hline $\begin{array}{llllllll}25-29 & \ldots & \ldots & \ldots & \ldots & \ldots & \ldots & \ldots\end{array}$ & 19.424 & 12.613 & 6.811 & 35,1 & 14.421 & 2.028 & 2.976 & 74,2 \\
\hline $\begin{array}{cccccccc}30-34 & \ldots & \ldots & \ldots & \ldots & \ldots & \ldots & \ldots\end{array}$ & 15.669 & 11.644 & 4.025 & 25,7 & 12.729 & 1.347 & 1.593 & 81,2 \\
\hline $\begin{array}{llllllll}35-39 & \ldots & \ldots & \ldots & \ldots & \ldots & \ldots & \ldots\end{array}$ & 11.162 & 8.777 & 2.386 & 21,4 & 9.521 & 833 & 808 & 85,3 \\
\hline $\begin{array}{llllllll}40-44 & \ldots & \ldots & \ldots & \ldots & \ldots & \ldots & \ldots\end{array}$ & 7.611 & 6.249 & 1.362 & 17,9 & 6.402 & 610 & 599 & 84,1 \\
\hline $\begin{array}{cccccccc}45-49 & \ldots & \ldots & \ldots & \ldots & \ldots & \ldots & \ldots\end{array}$ & 8.881 & 7.690 & 1.190 & 13,4 & 7.026 & 983 & 871 & 79,1 \\
\hline $\begin{array}{llllllll}50-54 & \ldots & \ldots & \ldots & \ldots & \ldots & \ldots & \ldots\end{array}$ & 8.119 & 7.154 & 965 & 11,9 & 6.195 & 975 & 949 & 76,3 \\
\hline $\begin{array}{llllllll}555 & \ldots 9 & \ldots & \ldots & \ldots & \ldots & \ldots & \ldots\end{array}$ & 7.229 & 6.446 & 783 & 10,8 & 5.282 & 961 & 986 & 73,1 \\
\hline 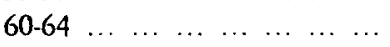 & 5.045 & 4.509 & 536 & 10,6 & 3.674 & 792 & 579 & 72,8 \\
\hline $\begin{array}{llllllll}65-69 & \ldots & \ldots & \ldots & \ldots & \ldots & \ldots & \ldots\end{array}$ & 3.737 & 3.494 & 243 & 6,5 & 2.774 & 494 & 469 & 74,2 \\
\hline $\begin{array}{llllllll}70.74 & \ldots & \ldots & \ldots & \ldots & \ldots & \ldots & \ldots\end{array}$ & 836 & 682 & 154 & 18,4 & 675 & 64 & 97 & 80,7 \\
\hline De 75 o más $\ldots \ldots \ldots \ldots \ldots$ & 417 & 383 & 34 & 8,2 & . 376 & 25 & 16 & 90,2 \\
\hline $\begin{array}{llllll}\text { Total } & \ldots & \ldots & \ldots & \ldots & \ldots\end{array}$ & 91.187 & 71.326 & 19.681 & 21,6 & 71.428 & 9.403 & 10.356 & 78,3 \\
\hline
\end{tabular}

Notas: El Personal con título superior de ciencias sanitarias se corresponde con el código 06, «Médicos, veterinarios, farmacéuticos y similares», de la Clasificación Nacional de Ocupaciones de 1979.

' Las mujeres representan en 1981 un 51 por 100 de la población.

2 El estrato rural incluye los núcleos de población con 2.000 habitantes o menos; el intermedio, desde 2.001 hasta 10.000 , y el urbano, 10.001 o más.

${ }^{3}$ El 63 por 100 de la población vive en estratos urbanos en 1981

Fuente: Instituto Nacional de Estadística, Censo de población de 1981. Tomo I. Vol. I. Resultados nacionales: Caracteristicas de la población (Madrid: INE, 1985), pp. 85-96. 


\section{TABLA 8}

Personal con título superior de ciencias sanitarias, por grupos de edad, sexo y estratos, en 1981 (En porcentajes)

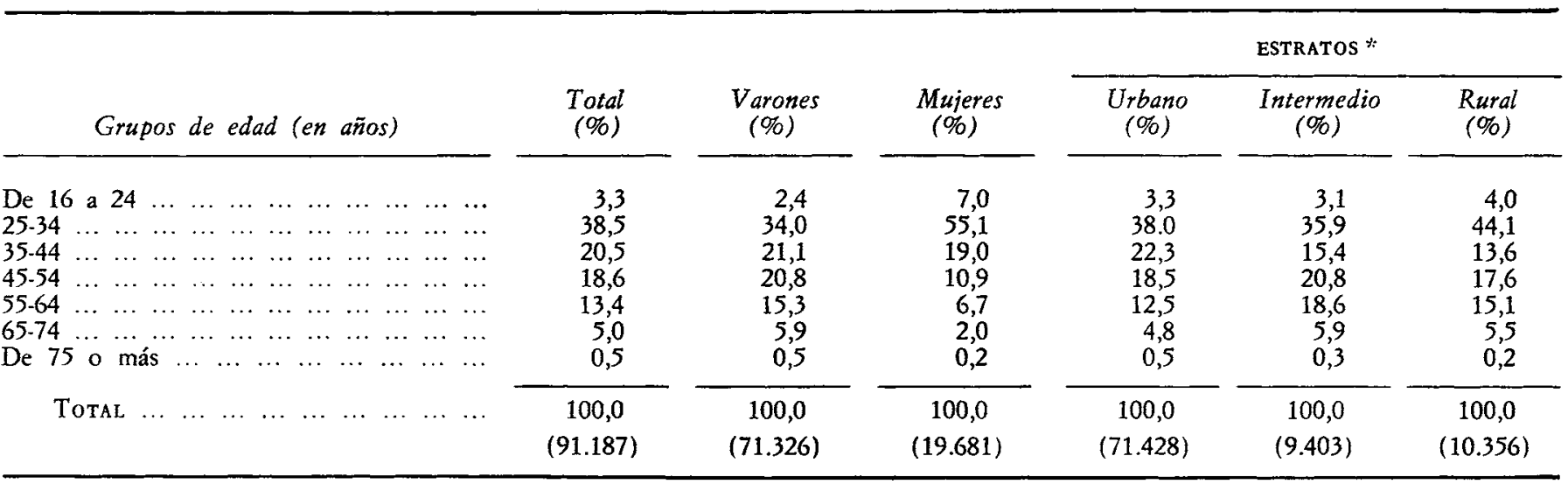

Notas: El Personal con título superior de ciencias sanitarias se corresponde con el código 06, «Médicos, veterinarios, farmacéuticos y similares», de la Clasificación Nacional de Ocupaciones de 1979.

* El estrato rural incluye los núcleos de población con 2.000 habitantes o menos; el intermedio, desde 2.001 hasta 10.000 , y el urbano, 10.001 o más.

Fuente: Instituto Nacional de Estadística, Censo de población de 1981. Tomo I. Vol. I. Resultados nacionales: Características de la población (Madrid: INE, 1985), pp. 85-96. 
conjunto de los/as profesionales ocupados ( 51 por 100). La causa de esta última disparidad consiste en que las carreras de ciencias sanitarias (sobre todo Medicina) son más prolongadas que el resto de las carreras universitarias.

En todas estas pautas existen notables diferencias por sexo. Tres de cada cinco licenciadas en ciencias sanitarias ocupadas en 1981 tienen menos de 35 años, mientras que son sólo dos de cada cinco licenciados. Esas proporciones se mantienen para el conjunto de la población activa ocupada, así como para el conjunto de los sectores de servicios. Cuanto más subimos en estratos de edad, más improbable es encontrar mujeres. Se puede afirmar que la generación de licenciadas de los años setenta (menores de 35 años en 1981) han logrado por vez primera la proporción de una a cuatro con respecto a los varones. Sin embargo, a partir de los 45 años las mujeres no representan más que una de cada diez personas ocupadas con licenciatura.

Un proceso de feminización similar se observa en las personas ocupadas en enfermería, aunque partiendo de una situación en la que las mujeres son ya mayoritarias. En 1981 hay unas 160.000 personas ocupadas en enfermería, que, según el Censo, incluye tanto a los ayudantes técnicos sanitarios como a los auxiliares en medicina, veterinaria y farmacia. El 78 por 100 son mujeres, y éstas predominan en mayor medida en los grupos de edades más jóvenes (véanse los datos en las tablas 9 y 10). El 86 por 100 de las personas ocupadas con edades comprendidas entre los 20 y los 24 años son mujeres. Esa proporción desciende hasta el 59 por 100 para el grupo de 55 a 59 años. Este descenso puede deberse a dos causas: que la mujer realmente se incorporó en menor proporción que el varón en el pasado, o que las enfermeras no han agotado su vida laboral para pasar a dedicarse a las tareas domésticas y de crianza de sus hijos/as. Del total de personas de 45 o más años, la proporción de mujeres es seis veces mayor en la enfermería que en las ciencias sanitarias. Para los de 29 años o menos, la proporción de mujeres en enfermería es sólo el doble que en las ciencias sanitarias. Este acercamiento entre ambas proporciones se observa hasta 1981 por la mayor entrada de las mujeres en la población ocupada con título de ciencias sanitarias, y no a causa de un mayor acceso de los varones a la profesión de enfermería. Es más, las mujeres continúan representando porcentajes superiores del empleo de enfermería a medida que se desciende por la pirámide de edades. El 23 por 100 del total de personas ocupadas en enfermería son menores de 25 años, mientras lo es el 17 por 100 de los varones y el 25 por 100 de las mujeres. No se puede, pues, hablar _-.por lo menos hasta 1981 - de una entrada importante en términos relativos de varones en la enfermería, sino de una perpetuación de la tendencia de las mujeres a representar proporciones cada vez mayores en ese grupo ocupativo.

El personal sanitario ha experimentado desde mediados de los años sesenta un proceso de urbanización. A medida que avanza la edad, hasta llegar a los 44 años, las personas ocupadas en sanidad residen cada vez más en zo- 


\section{TABLA 9}

Personal de enfermería por grupos de edad, sexo y estratos en 1981 (En números absolutos)

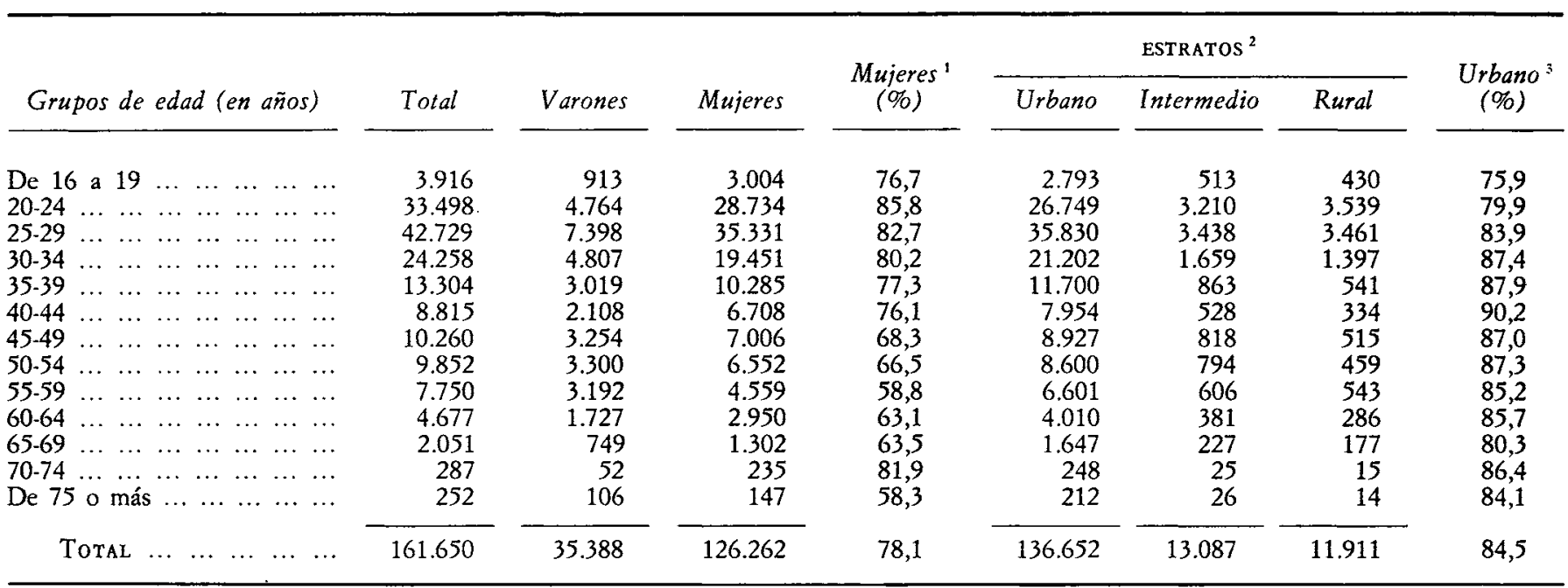

Notas: El Personal de enfermeria se corresponde con el código 07, «Ayudantes técnicos sanitarios y Auxiliares en medicina, veterinaria y farmacia», de la Clasificación Nacional de Ocupaciones de 1979.

${ }^{1}$ Las mujeres representan en 1981 un 51 por 100 de la población.

${ }^{2}$ El estrato rural incluye los núcleos de población con 2.000 habitantes o menos; el intermedio, desde 2.001 hasta 10.000, y el urbano, 10.001 o más.

${ }^{3}$ El 63 por 100 de la población vive en estratos urbanos en 1981

Fuente: Instituto Nacional de Estadística, Censo de población de 1981. Tomo I. Vol. I. Resultados nacionales: Características de la población (Madrid: INE, 1985), pp. 85-96. 
TABLA 10

Personal de enfermeria por grupos de edad, sexo y estratos en 1981 (En porcentajes)

\begin{tabular}{|c|c|c|c|c|c|c|}
\hline \multirow[b]{2}{*}{ Grupos de edad (en años) } & \multirow[b]{2}{*}{$\begin{array}{l}\text { Total } \\
(\%)\end{array}$} & \multirow[b]{2}{*}{$\begin{array}{c}\text { Varones } \\
(\%)\end{array}$} & \multirow[b]{2}{*}{$\begin{array}{l}\text { Mujeres } \\
(\%)\end{array}$} & \multicolumn{3}{|c|}{ ESTRATOS * } \\
\hline & & & & $\begin{array}{c}\text { Urbano } \\
(\%)\end{array}$ & $\begin{array}{l}\text { Intermedio } \\
(\%)\end{array}$ & $\begin{array}{l}\text { Rural } \\
(\%)\end{array}$ \\
\hline 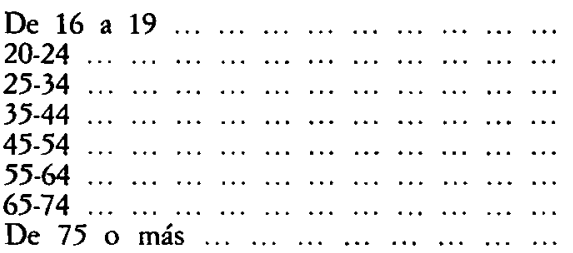 & $\begin{array}{r}2.4 \\
20,7 \\
41,4 \\
13,7 \\
12,4 \\
7,7 \\
1,5 \\
0,2\end{array}$ & $\begin{array}{r}2,6 \\
13,5 \\
34,5 \\
14,5 \\
18,5 \\
13,9 \\
2,2 \\
0,3\end{array}$ & $\begin{array}{r}2,4 \\
22,8 \\
43,4 \\
13,4 \\
10,7 \\
5,9 \\
1,2 \\
0,1\end{array}$ & $\begin{array}{r}2,2 \\
19,6 \\
41,7 \\
14,3 \\
12,8 \\
7,7 \\
1,4 \\
0,2\end{array}$ & $\begin{array}{r}3,9 \\
24,5 \\
39,0 \\
10,4 \\
12,4 \\
7,5 \\
1,9 \\
0,2\end{array}$ & $\begin{array}{r}3,6 \\
29,7 \\
40,8 \\
9,0 \\
8,2 \\
7,0 \\
1,6 \\
0,1\end{array}$ \\
\hline $\begin{array}{llllllllll}\text { Total } & \ldots & \ldots & \ldots & \ldots & \ldots & \ldots & \ldots & \ldots & \ldots\end{array}$ & $\begin{array}{c}100,0 \\
(161.650)\end{array}$ & $\begin{array}{c}100,0 \\
(35.388)\end{array}$ & $\begin{array}{c}100,0 \\
(126.262)\end{array}$ & $\begin{array}{c}100,0 \\
(136.652)\end{array}$ & $\begin{array}{c}100,0 \\
(13.087)\end{array}$ & $\begin{array}{c}100,0 \\
(11.911)\end{array}$ \\
\hline
\end{tabular}

Notas: El Personal de enfermeria se corresponde con el código 07, «Ayudantes técnicos sanitarios y Auxiliares en medicina, veterinaria y farmacia», de la Clasificación Nacional de Ocupaciones de 1979.

* El estrato rural incluye los núcleos de población con 2.000 habitantes o menos; el intermedio, desde 2.001 hasta 10.000 , y el urbano, 10.001 o más.

Fuente: Instituto Nacional de Estadística, Censo de población de 1981. Tomo I. Vol. I. Resultados nacionales: Características de la población (Madrid: INE, 1985), pp. 85-96. 
nas urbanas. A partir de ese momento, la tasa de urbanización decrece hasta los 69 años, para aumentar de nuevo con motivo de la mayor tasa de mortalidad de los varones (que residen en zonas rurales e intermedias en mayor proporción). Ese fenómeno puede explicarse teniendo en cuenta la gran entrada de personal hospitalario (esencialmente enfermeras) en los años setenta, que hace que el grupo de edad entre 30 y 44 años tenga tasas de urbanización elevadas ( 88 por 100 ). Las cohortes posteriores ya no encuentran trabajo tan fácilmente en los núcleos urbanos y tienen que emplearse en el medio rural. Las personas menores de 35 años suponen el 52 por 100 de todos los empleados/as en los núcleos urbanos, mientras que son el 60 por 100 de los empleados/as en las zonas rurales. Por el contrario, las personas comprendidas entre los 35 y los 64 años son el 46 por 100 en los núcleos urbanos y sólo el 37 por 100 de los ocupados en los rurales.

Más que una contracción del estrato urbano-hospitalario se puede hablar de una expansión de los estratos rurales e intermedios. Es decir, el personal sanitario que ha entrado en el sector durante los últimos años de la década de los setenta tiene una mayor tendencia hacia el medio rural que el que ingresó diez o quince años antes. Las tasas de urbanización progresivamente menores de las personas mayores de 44 años se explican también por el fenómeno de expansión del empleo hospitalario de los años setenta, que no afectó a esos grupos de edad.

Las personas licenciadas de ciencias sanitarias ocupadas trabajan esencialmente en los núcleos urbanos, aunque en menor proporción que las empleadas en enfermería. El proceso comenzó a finales de los años sesenta y prosiguió hasta mediados de la década siguiente. Desde entonces, la tendencia a trabajar en las zonas urbanas de los varones con licenciatura sanitaria se ha debilitado. La tasa de urbanización total (de varones y mujeres) es alta, el 78 por 100 en 1981. Esa tasa describe una trayectoria ascendente desde el grupo de edad de 25 a 29 años ( 74 por 100) hasta el de 35 a 39 años ( 85 por 100); a partir de entonces la tendencia es decreciente hasta el grupo de 55 a 59 años (73 por 100), mientras los comprendidos entre los 65 y los 69 años trabajan en núcleos urbanos en un 81 por 100 , y las personas mayores de 75 años en un 90 por 100 , debido a que sólo pueden seguir trabajando las personas que lo hacen por cuenta propia (grupo que es mayoritario en los estratos intermedios y rurales). Es decir, las nuevas cohortes de personas licenciadas están trabajando más en los núcleos no-urbanos que las que comenzaron a trabajar en la década de los sesenta. Las personas licenciadas ocupadas que son menores de 35 años representan el 41 por 100 del total en los núcleos urbanos y el 48 por 100 en los rurales. Los comprendidos entre 35 y 54 años representan también el 41 por 100 del total en los núcleos urbanos, pero sólo el 32 por 100 en los rurales. De nuevo se comprueba un proceso de ruralización de las personas licenciadas menores de 35 años, quienes no han encontrado trabajo 
en las ciudades en igual medida que lo lograron los que comenzaron a trabajar en los años sesenta y principios de los setenta.

Las mayores tasas de urbanización (en torno a los 40-44 años) no se corresponden exactamente con el boom hospitalario de los años setenta. Una hipótesis es que las personas que trabajan en enfermería accedieron a empleos urbanos tras unos años de trabajar en las zonas intermedia o rural, o quizá tras permanecer inactivas o paradas. En este último caso, el equilibrio en el mercado de trabajo de la enfermería se habría verificado a partir de un exceso inicial de demanda gracias a la mayor oferta de puestos de trabajo (hospitalarios-urbanos), quizá como consecuencia de la presión de los desempleados. Una explicación alternativa es que las tituladas de enfermería (que son mayoritarias en la profesión) tuvieron hijos/as primero, incorporándose después al trabajo unos años más tarde. También es posible que la crisis económica impulsara a enfermeras inactivas a incorporarse al mercado de trabajo en busca de un segundo sueldo familiar.

Observamos, por tanto, que el personal sanitario es en 1981 joven, particularmente en el caso de las mujeres. La población ocupada total no es tan joven como lo es la sanitaria, ni tampoco las personas ocupadas en el conjunto de los sectores de servicios. Las mujeres del sector sanitario, que son más numerosas que los varones, son también más jóvenes (esto aparece más claro en el gráfico 1). Se observa la huella perdurable que dejó la guerra civil de 1936-39 en la población ocupada: la cohorte entre los 40 y los 45 años de edad es más reducida de lo esperable. En el caso de las mujeres, la bajada de la natalidad de los años de la guerra es menos profunda que para los varones. Se observa también que más de la mitad de las personas ocupadas en el sector sanitario tienen menos de 35 años, situación bien distinta a la del conjunto de los sectores de servicios y a la de la población ocupada total. Resulta curioso notar cómo las mujeres ocupadas en sanidad 'son minoritarias desde los 50 años en adelante, cuando para las personas menores de 30 años son más del doble de numerosas que los varones. Se puede afirmar que el proceso de feminización comenzó hacia mediados de los años sesenta.

En los años ochenta - caracterizados ya por un progresivo envejecimiento de la población-, las personas que han de cuidar de los enfermos/as son excepcionalmente jóvenes y, además, en su mayoría mujeres. La realidad del sector sanitario es que personas cada vez más jóvenes (sobre todo mujeres) cuidan (y cuidarán) de unas personas enfermas cada vez de mayor edad. $E l$ sector sanitario es un sector de mujeres y, en segundo lugar, de jóvenes. Esta realidad es distinta a la que preside el conjunto de las actividades económicas: el sector sanitario mejoró - de modo parcial y desigual - su carencia de personal sanitario durante los años setenta. Como apunta Hofoss (1986: 208), la entrada de profesionales jóvenes en el sector sanitario ha supuesto un alivio de la carencia de personal en los países occidentales, pero coloca al sector en una difícil situación si se pretenden mantener las tasas de entrada de las nue- 


\section{GRAFICO 1}

Personal trabajando, por sectores, sexo y grupos de edad, en 1981

(En números absolutos)

POBLACION OCUPADA TOTAL

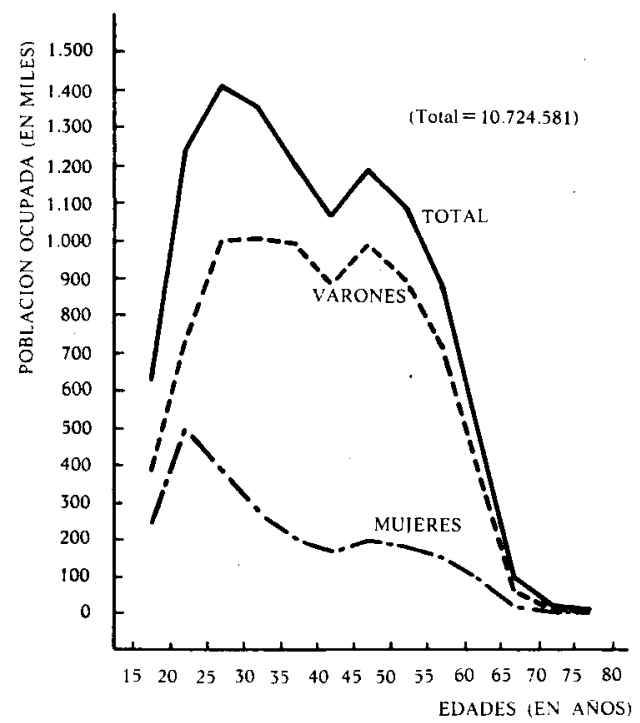

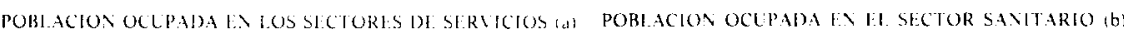

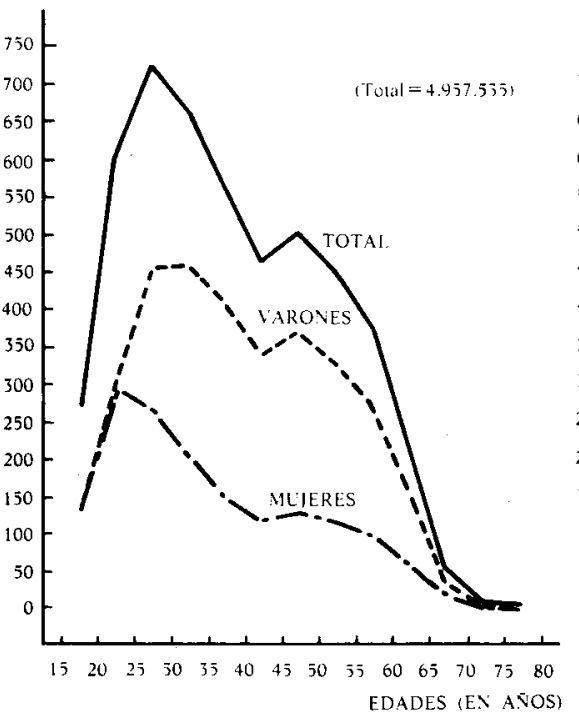

$(T+110)=\$ 10.567)$

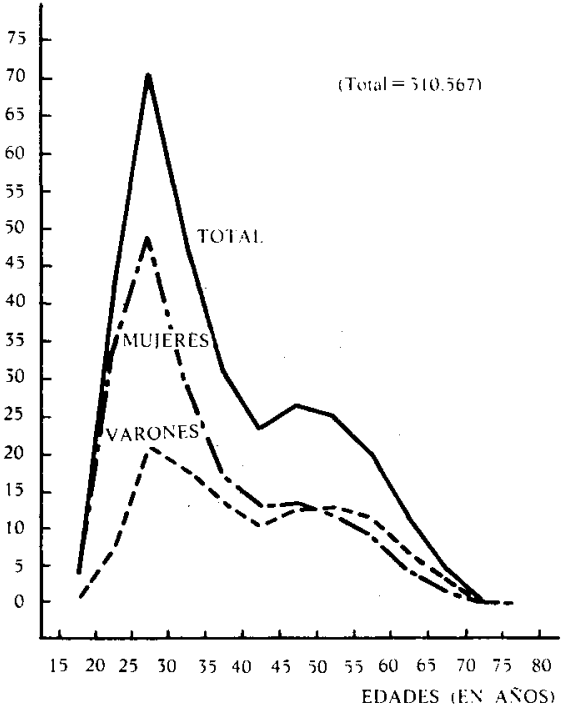

Notas: Las mujeres representan en 1981 un 51 por 100 de la población.

(a) Los sectores de servicios abarcan los códigos 61 a 67, 71 a 76 y 91 a 99 de la Clasificación Nacional de Actividades Económicas (CNAE) de 1974.

(b) El sector sanitario se corresponde con "Sanidad y servicios veterinarios" (código 93 de la CNAE de 1974).

Fuente: Instituto Nacional de Estadística, Censo de población de 1981. Tomo I. Vol. 1. Resultados nacionales: Caracteristicas de la población (Madrid: INE. 1985), pp. 81-84. 
vas personas que están concluyendo sus estudios de ciencias sanitarias y enfermería.

Los procesos de rejuvenecimiento y feminización del empleo en el sector sanitario son desiguales por sexo y por estratos ocupativos. Así, el grupo que más se ha rejuvenecido ha sido el personal de enfermería, mientras que el grupo de las personas licenciadas en ciencias sanitarias no ha experimentado un proceso tan acentuado. Además, como se puede apreciar en el gráfico 2, el proceso de rejuvenecimiento del personal de enfermería ha sido posterior al de las personas licenciadas en ciencias sanitarias; el desfase temporal entre ambos parece ser de unos diez o quince años. El personal de enfermería se ha rejuvenecido más rápidamente, con más intensidad $\mathrm{y}$, por tanto, de modo más radical que el que tiene título de ciencias sanitarias. Eso era esperable, puesto que la variable causal principal -el crecimiento del sector hospitalario- afectó esencialmente al número de enfermeras/os que encontraron trabajo durante los años setenta. El proceso de rejuvenecimiento ha afectado, pues, en mayor medida a las mujeres (enfermería) que a los varones (ciencias sanitarias). El gráfico 2 permite comprobar, además, que se ha producido ciertamente un proceso de feminización de la ocupación con título superior, que ha sido (y es) un colectivo de varones (en 1950 representaban el 97 por 100 del total); pero la población ocupada en enfermería (mujeres) es cada vez más femenina.

\section{El futuro del personal sanitario}

Uno de los rasgos más significativos de la evolución del empleo en el sector sanitario es la progresiva incorporación de mujeres durante los últimos años. Mientras que solamente dos de cada cien varones ocupados trabajan en sanidad en 1981, las mujeres del sector sanitario suponen más de una de cada diez ocupadas para algunos grupos de edad. En el gráfico 3 se observa que las mujeres y los varones que trabajan en sanidad representan porcentajes del total de la población ocupada según pautas diferentes. Más de una de cada diez mujeres ocupadas menores de 35 años trabaja en el sector sanitario, representando éste solamente el 3 por 100 del empleo total. Hay que tener en cuenta, sin embargo, que las profesiones de ciencias sanitarias no han experimentado una afluencia tan importante de mujeres como la profesión de enfermería (véase el gráfico 3 ).

Como se aprecia también en el gráfico 3, las mujeres-enfermeras ocupadas son relativamente más numerosas en los grupos de edad inferiores, lo que no ocurre con las mujeres-licenciadas. A pesar de que las carreras sanitarias superiores (Medicina, Veterinaria y Farmacia) se han feminizado considerablemente, las licenciadas sanitarias menores de 35 años no representan porcentajes importantes del total de mujeres ocupadas. Es cierto que hay cada vez 


\section{GRAFICO 2}

Personal con título de enfermería y ciencias sanitarias, por sexo y grupos de edad, en 1981

(En números absolutos)

ENFERMERIA
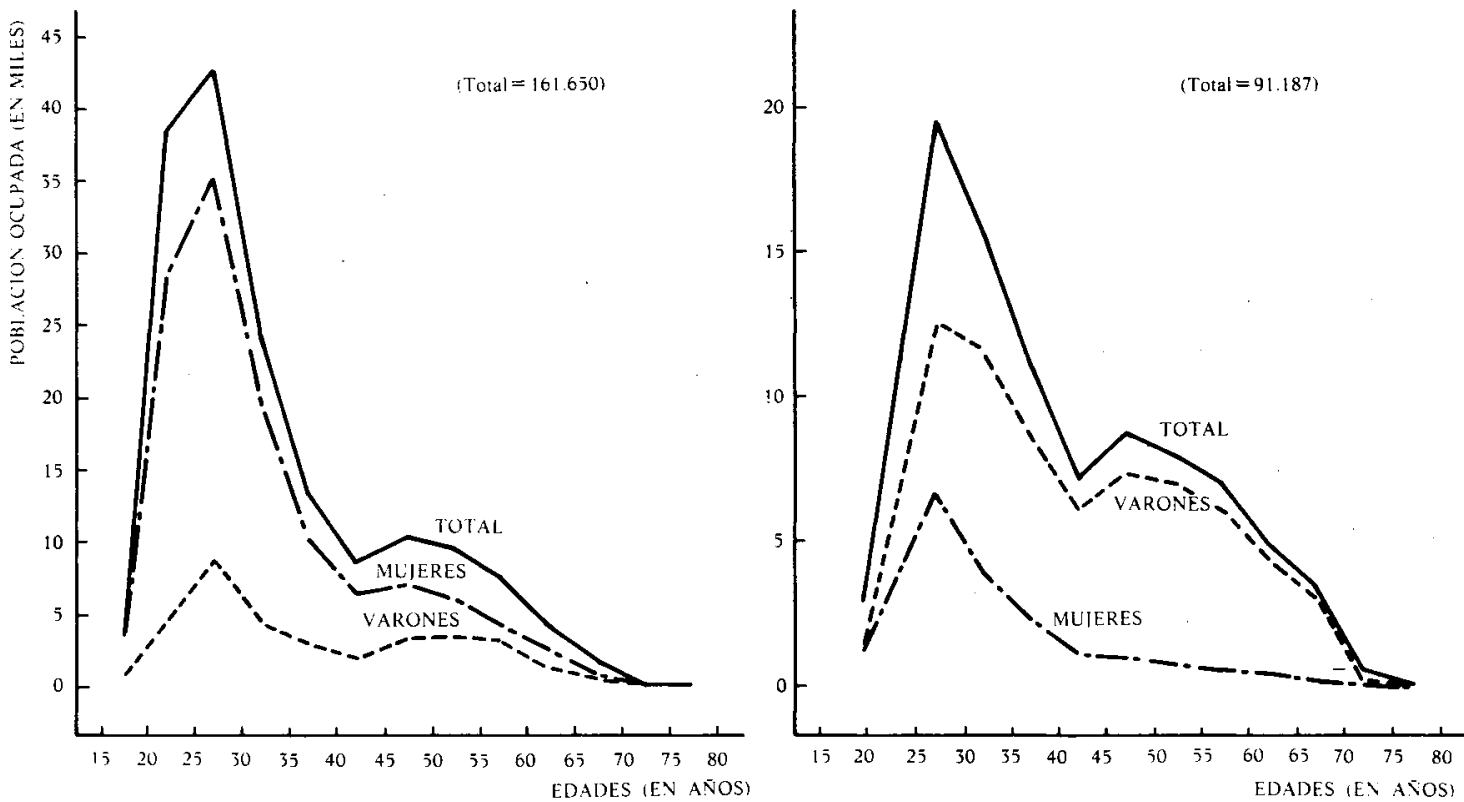

Nota: La población ocupada con título de enfermería incluye los "Ayudantes técnicos sanitarios y Auxiliares en medicina, veterinaria y farmacia", código 07 de la Clasificación Nacional de Ocupaciones (CNO) de 1979. terinarios, farmacéuticos y similares", código 06 de la CNO de 1979.

Fuente: Instituto Nacional de Estadistica, Censo de población de 1981. Tomo I. Vol. I. Resultados nacionales: Caracteristicas de la población (Madrid: INE. 1985), pp. 85-96. 


\section{GRAFICO 3}

Personal sanitario del total de población ocupada, en 1981

(En porcentajes de la población ocupada)
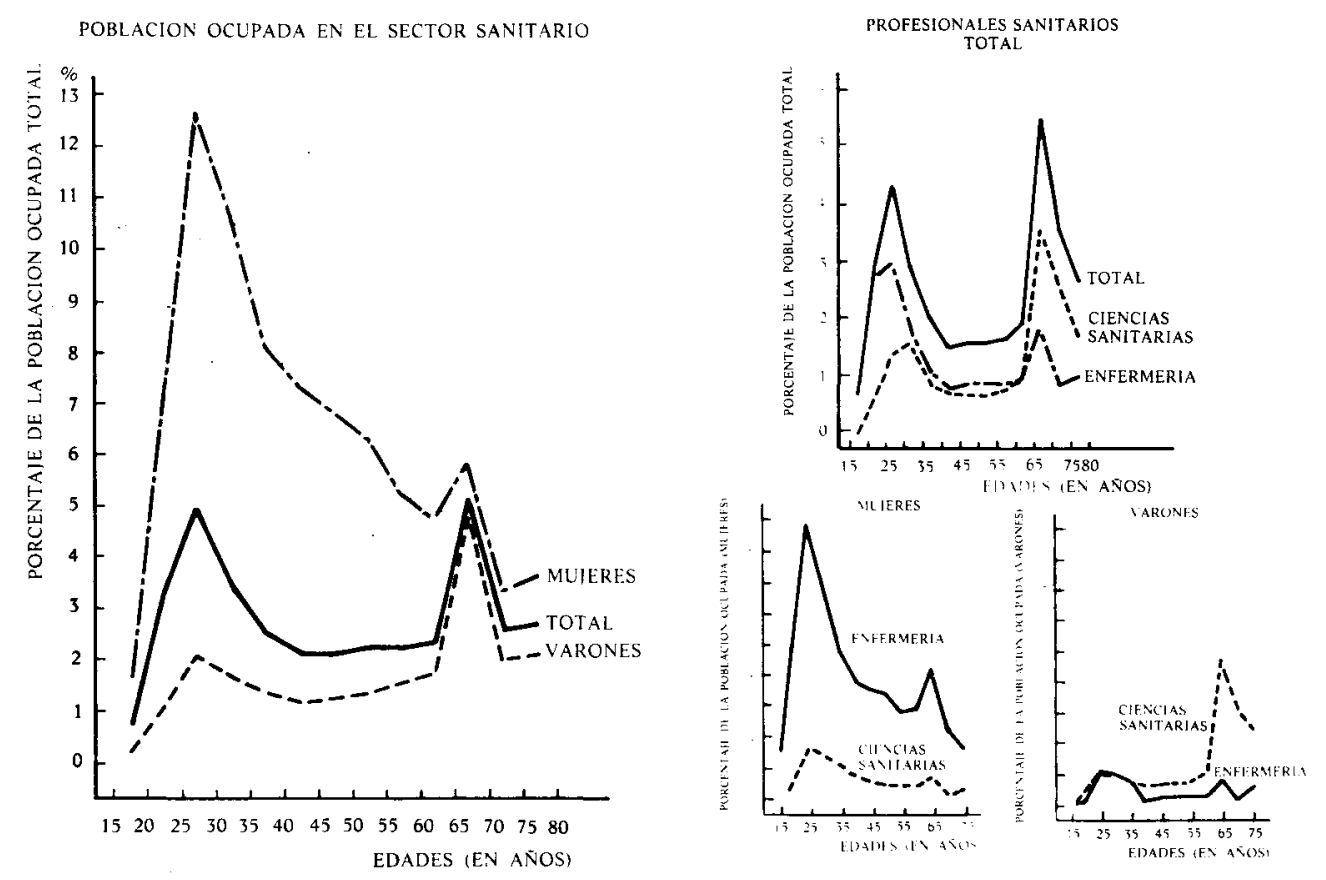

Nota: El sector sanitario se corresponde con el codigo 94. "Sanidad y servicios veterinarios". de la Clasificacion Nacional de Actividades Económicas. Las ciencias sanitarias incluyen el código 06, "Médicos, veterinarios, farmacéuticos y similares", y la entermeria el código 07, "Ayudantes técnicos sanitarios y Auxiliares en medicina, veterinaria y farmacia". de la Clasificación Nacional de Ocupaciones.

Fuente: Instituto Nacional de Estadística, Censo de población de 1981. Tomo 1. Vol. I. Resultados nacionales: Caracteristicas de la población (Madrid: INE, 1985), pp. 75-81 y 85-90. 
más licenciadas ocupadas, pero hay muchas más enfermeras ocupadas también. Entre las mujeres ocupadas con edades comprendidas entre 25 y 35 años, el 9 por 100 trabaja en enfermería y sólo el 2 por 100 en ciencias sanitarias; esta diferencia no es tan grande para los grupos de edad superiores. Los varones, en cambio, parece que se incorporan a las profesiones de enfermería y de ciencias sanitarias en igual proporción desde hace quince o veinte años (gráfico 3).

Podemos afirmar, pues, que la dinámica del sector sanitario tiende a confirmar un modelo dual: varón-licenciado y mujer-enfermera. La estructura de edades del personal sanitario indica una consolidación (cuando no una intensificación) de las desigualdades ocupativas entre varones y mujeres, básicamente entre licenciados y diplomadas.

En los treinta últimos años (1950-81), el número de personas ocupadas en el sector sanitario se ha triplicado, superando ya las 310.000 . A esta cifra se pueden añadir los estudiantes de ciencias sanitarias y de enfermería (aproximadamente 160.000 ) y las personas dedicadas a la docencia, con lo que el sector sanitario en sentido amplio reúne ya actualmente a un colectivo de medio millón de personas. El número de profesionales sanitarios (personas licenciadas en Medicina, Veterinaria, Farmacia, así como ayudantes técnicos sanitarios, auxiliares en Medicina, Veterinaria o Farmacia) supera ya el cuarto de millón. Más de la mitad de las personas ocupadas en sanidad son mujeres, y más de las tres cuartas partes viven en núcleos urbanos. Aparte hay que tener en cuenta que las mujeres son más urbanas en cuanto a su residencia actual que los varones.

La ocupación sanitaria se caracteriza por una importante jerarquización por sexos y por su desigual distribución territorial. La mayoría de las mujeres empleadas en sanidad son enfermeras. El modelo varón-licenciado y mujerenfermera se cumple hasta el punto de que sólo una de cada cinco personas ocupadas que son licenciadas de ciencias sanitarias es mujer, pero lo son cuatro de cada cinco personas trabajando en enfermería. Además, la distribución geográfica de los profesionales sanitarios sigue una pauta Norte-Sur, pues todo el Sur peninsular (y Galicia) padece una relativa escasez de trabajadores sanitarios, mientras el Norte está comparativamente bien dotado. El personal sanitario parece concentrarse en zonas: 1) de renta per capita elevada; 2) con estructuras de propiedad privada que permiten a la población costearse la asistencia sanitaria, y 3) con centros universitarios y sistemas hospitalarios importantes.

Desde finales de los años sesenta se han producido, además, otros tres procesos de jerarquización que han cambiado las características ocupativas del sector: el personal sanitario es en 1981 más joven, femenino y urbano que quince años atrás. El proceso de rejuvenecimiento ha llevado a una situación en que más de la mitad de las personas ocupadas en el sector son menores de 35 años. Casi la mitad de las personas licenciadas en ciencias sanitarias con- 
cluyeron sus estudios en los años setenta, aunque el personal de enfermería es aún más joven. El proceso de feminización se ha producido tanto en las ciencias sanitarias como en la enfermería. Las mujeres han pasado de representar el 3 por 100 de las personas licenciadas en 1950 a ser el 22 por 100 en 1981. En enfermería, pese a que ya era una profesión mayoritariamente femenina hace treinta años, las mujeres tienden a representar una proporción cada vez mayor.

El sector sanitario español ha experimentado en los últimos quince años un acelerado proceso de cambio (asalarización, rejuvenecimiento, feminización y urbanización), que va a producir unas consecuencias importantes para el futuro. Es muy probable que el sector no pueda proseguir contratando personal asalariado al mismo ritmo que lo hizo durante los años de la expansión hospitalaria. Los nuevos criterios políticos y planificadores indican que existe un deseo de contención del gasto sanitario y una reorientación del esfuerzo público hacia la atención primaria de salud (APS), en detrimento de la hospitalaria. Es esperable que el sector no vaya a acoger a tantos nuevos asalariados como antes, ni de la misma formación. El rejuvenecimiento del personal sanitario puede provocar también una disminución de la tasa de mortalidad profesional y un agravamiento del problema del desempleo de las personas licenciadas de ciencias sanitarias, como prevé el propio Ministerio de Sanidad y Consumo (Nadal, 1984: 17).

El papel de las mujeres trabajadoras en el sector sanitario se ha vuelto aún más confuso tras el crecimiento del sector hospitalario durante los años setenta. No sólo no han conseguido una equiparación profesional a los varones, sino que la situación parece haberse complicado aún más, si bien hay cada vez más mujeres licenciadas en ciencias sanitarias, especialmente farmacéuticas. Farmacia se ha convertido en estos años en una profesión mayoritariamente femenina, por vez primera en su historia. Dado que las mujeres continúan incorporándose en proporciones cada vez mayores a las carreras superiores de ciencias sanitarias, es previsible que muchas de ellas se enfrenten a largos períodos de desempleo o que renuncien a incorporarse al mercado de trabajo. La dinámica del sector puede llevar a que las mujeres en posesión de títulos profesionales sanitarios trabajen eventualmente por cortos períodos de tiempo, y a que subsistan en una situación profesional discriminatoria respecto a los varones. Paradójicamente, el sector sanitario español mantiene un número todavía bajo de médicas y de personas que trabajen en enfermería.

El mayor apoyo que previsiblemente se va a dar a la APS puede provocar una intensificación del tímido proceso de ruralización que se observa en el empleo sanitario. Al contrario de lo que ocurre en el resto de las actividades de servicios, la sanidad parece huir de los grandes centros productores de servicios ubicados en zonas urbanas (hospitales) para acercar la asistencia a la población; a causa de eso se produce un traslado de personal o bien una mayor contratación de nuevo personal en las zonas no-urbanas. Sin embargo, es 
arriesgado establecer aún esa tendencia, así como la concentración de recursos para la APS versus el sector hospitalario es más un proyecto que una realidad en los presupuestos.

En los próximos lustros el sector sanitario se enfrenta, pues, con nuevos procesos de cambio que, supuestamente, van a tender a reducir el desigual crecimiento por zonas geográficas, grupos profesionales, estratos rurales/urbanos y sexos. Tratando de cubrir necesidades sanitarias centenarias, el crecimiento en los recursos sanitarios de los años setenta ha incrementado, sin embargo, las desigualdades ocupativas dentro del sector. Los años que cerrarán el milenio serán decisivos para que el sector sanitario español consiga: 1) una distribución de sus recursos de capital humano menos desigual; 2) reduzca los procesos de dominación, discriminación y dependencia dentro del propio personal sanitario, y 3) establezca una planificación en armonía con las necesidades reales de la población.

\section{BIBLIOGRAFIA}

Bernard KRIEF Consultants for EuRope (1976a): Intorme-resumen sobre la prospectiva de las profesiones liberales en los años 1980-1985, Madrid: Banco de Santander, $47 \mathrm{pp}$.

- (1976 6): Informe-resumen para orientación profesional. Prospectiva Profesional 80-85, Madrid: Banco de Santander, $16 \mathrm{pp}$.

- (1980): Estudio prospectivo de la profesión de médico en España en la década de los 80, Madrid: Banco de Santander.

Cuadrado, J. R. (1986): «La evolución del empleo en los servicios», Papeles de Economía Española, 26: 131-155.

De Kervasdoué, Jean, et al. (1984): The End of an Illusion: The Future of Health Policy in Western Industrialized Nations, Berkeley (California): University of California Press.

De Miguel, Amando (1974): Manual de estructura social de España, Madrid: Tecnos, $590 \mathrm{pp}$.

De Miguel, Jesús M. (1976): La reforma sanitaria en España: El capital humano en el sector sanitario, Madrid: Cambio 16, 263 pp.

- (1983): Estructura del sector sanitario, Madrid: Tecnos, 159 pp.

- (1986 a): "Health sector structures: The case of Spain», Social Science and Medicine, 22, núm. 2: 233-246.

- (1986 b): La profesión farmacéutica del año 2000, Madrid: Ministerio de Sanidad y Consumo.

Del Campo, Salustiano (1964): Problemas de la profesión médica española: Informe preliminar, Madrid: Comisión Nacional Española del Instituto Internacional de Estudios de Clases Medias.

Domínguez-Alcón, Carmen; Rodríguez, Josep A., y De Miguel, Jesús M. (1983): Sociología y Enfermería, Madrid: Pirámide, 207 pp.

Durán, María Angeles (1983): Desigualdad social y enfermedad, Madrid: Tecnos, 180 pp.

Freidson, Elliot (1978): La profesión médica, Barcelona: Península, 373 pp.

- (1986): Professional Powers. A Study of the Institutionalization of Formal Knowledge, Chicago y Londres: The University of Chicago Press, 241 pp. 
Fuchs, Victor R. (1968): The Service Economy, Nueva York: National Bureau of Economic Research, $280 \mathrm{pp}$.

- (1974): Who Shall Live? Health, Economics, and Social Choice, Nueva York: Basic Books.

- (1986): The Healtb Economy, Cambridge (Massachusetts): Harvard University Press, $401 \mathrm{pp}$.

Garmendia, J. A. (1986): «¿Hacia dónde va el empleo?», Sistema, 74: 51-52.

GONZÁlez, Benjamín (1979): El capital bumano en el sector sanitario: La distribución de médicos en España, Madrid: Centro de Investigaciones Sociológicas, 115 pp.

Hofoss, V. R. (1986): «Health professions: The origin of species», Social Science and Medicine, 22, núm. 2: 201-209.

JefFerys, Margot, y SaChs, Hessie (1983): Rethinking General Practice: Dilemmas in Primary Health Care, Nueva York: Tavistock.

LEwIN, Ellen, y OiESEN, Virginia (eds.) (1985): Women, Health, and Healing: Toward a New Perspective, Nueva York: Tavistock.

Martín Barroso, Clemente (1978): Enfermería: Presente y futuro, Madrid: Colegio Oficial de Ayudantes Técnicos Sanitarios.

Martín López, Enrique (ed.) (1983): «Seguridad Social, Sanidad y Servicios sociales en España (1975-1982)», en Fundación FOESSA: Informe sociológico sobre el cambio social en España, 1975-1983. IV Informe FOESSA. Volumen II, Madrid: Euramérica, 1983 , pp. 827-916.

Martín Moreno, Jaime, y De Miguel, Amando (1982): Sociología de las profesiones en España, Madrid: Centro de Investigaciones Sociológicas, 200 pp.

MCGuiRe, Christine H. (1983): Handbook of Health Professions Education. Responding to New Realities in Medicine, Dentistry, Pharmacy, Nursing, Allied Health, and Public Health, San Francisco (California): Jossey-Bass, 543 pp.

MCKInLEY, John B. (ed.) (1985): Issues in the Political Economy of Health Care, Nueva York: Tavistock.

Moline, J. N. (1986): «Professionals and professions: A philosophical examination of an ideal», Social Science and Medicine, 22, núm. 5: 501-508.

NADAL, Julio (ed.) (1984): Oferta y demanda de médicos en España: Una primera aproximación, Madrid: Ministerio de Sanidad y Consumo, 95 pp.

Pinilla de las Heras, Esteban, y VIDAL, Ramón (1977): Entermos, médicos y bospitales: Una imagen sociológica sobre la medicina bospitalaria, Barcelona: Ciba-Geigy, $128 \mathrm{pp}$.

Rodríguez, Josep A. (1986): Salud y Sociedad: Análisis sociológico de la estructura y dinámica del sector sanitario español (tesis doctoral), Oviedo (Asturias): Facultad de Ciencias Económicas y Empresariales de la Universidad de Oviedo, 441 pp. En prensa en la Editorial Tecnos (Madrid, 1987).

Srdel, Victor W., y SrDel, Ruth (1984): Reforming Medicine. Lessons of the Last Quarter Century, Nueva York: Pantheon Books.

Study Commission on Pharmacy (1975): Pbarmacists for the Future, Ann Arbor (Michigan): Health Administration Press, 161 pp.

Subsecretaría de la Seguridad Social (1977): Libro Blanco de la Seguridad Social, Madrid: Ministerio de Trabajo, 743 pp. 
NOTAS DE INVESTIGACION 